\title{
Prevalence of Anxiety Disorders and Subthreshold Anxiety Throughout Later Life: Systematic Review and Meta-Analysis
}

\author{
Maartje Witlox ${ }^{1}$, Nadia Garnefski ${ }^{1}$, Vivian Kraaij $^{1}$, Meropi Simou ${ }^{1,2}$, Elise Dusseldorp ${ }^{1}$, Ernst Bohlmeijer ${ }^{3}$, \\ and Philip Spinhoven ${ }^{1}$ \\ ${ }^{1}$ Department of Clinical Psychology, Leiden University \\ ${ }^{2}$ Greek Association for Cognitive and Behavioural Psychotherapies, Thessaloniki, Greece \\ ${ }^{3}$ Department of Psychology Health and Technology, University of Twente
}

\begin{abstract}
This systematic review and meta-analysis compared prevalence rates for subthreshold anxiety and anxiety disorders in adults aged 55+ and examined if these rates were associated with age. A systematic search and screening procedure resulted in 46 included articles. First, prevalence rates for subthreshold anxiety and anxiety disorders were statistically compared. Subthreshold panic, generalized anxiety and specific phobia were significantly more prevalent than the corresponding clinical disorders. In general, subthreshold anxiety appeared to be at least similarly prevalent to anxiety disorders, although firm conclusions are precluded due to the small number of samples that could be included in the analyses and the large heterogeneity between the reported prevalence rates. Second, using subgroup analyses, pooled prevalence rates for four age groups of older adults $(55-64,65-74,75-84,85+)$ were compared. For specific phobia, the $75-84$ and $85+$ groups had significantly lower prevalence rates than the 55-64 and 65-74 groups. Posttraumatic stress disorder was significantly more prevalent in the 55-64 group than in the other age groups, and lowest in the $85+$ group. No other significant differences between age groups were found. The association between later life subthreshold anxiety and age could not be examined due to a lack of reported information. The main limitation of this study is the small number of samples in the analyses, which limits their power and generalizability.
\end{abstract}

Keywords: older adults, anxiety disorders, subthreshold anxiety, prevalence, meta-analysis

Epidemiological studies have repeatedly demonstrated that anxiety disorders are among the most common mental health issues in older adults, although prevalence rates are lower than those in younger adults (Beekman et al., 1998; Canuto et al., 2018; Gum et al., 2009; Préville et al., 2008; Reynolds et al., 2015; Ritchie et al., 2004). While this general finding has been well-established, some issues regarding the prevalence of anxiety in later life remain unsolved. The current article aims to address two of these issues using a systematic review and meta-analysis.

This article was published Online First November 12, 2020

Nadia Garnefski (D) https://orcid.org/0000-0003-1198-0502

Vivian Kraaij (D) https://orcid.org/0000-0003-1146-177X

Meropi Simou (D) https://orcid.org/0000-0003-1971-7354

Elise Dusseldorp (D) https://orcid.org/0000-0002-6305-4060

Ernst Bohlmeijer (D) https://orcid.org/0000-0002-7861-1245

Philip Spinhoven (D) https://orcid.org/0000-0002-4117-335X

All authors designed the study. Authors Maartje Witlox and Meropi Simou conducted the search and article selection. Authors Maartje Witlox and Elise Dusseldorp conducted and interpreted the statistical analyses. All authors provided comments on initial drafts of the manuscript. All authors contributed and have approved of the final manuscript.

A review protocol was submitted to PROSPERO (registration: CRD42018092953). The protocol can be assessed at https://www.crd.york .ac.uk/PROSPERO.

Correspondence concerning this article should be addressed to Maartje Witlox, Department of Clinical Psychology, Leiden University, Wassenaarseweg 52, 2333AK, Leiden, the Netherlands. Email: m.witlox@ fsw.leidenuniv.nl
First, although many studies have assessed the prevalence of anxiety disorders in older adults, little is known about the prevalence of subthreshold anxiety. Subthreshold anxiety can be broadly defined as increased levels of anxiety without the symptomatology meeting diagnostic criteria for a full-blown anxiety disorder, but at the moment there is no consensus about the best exact definition (Rivas-Vazquez et al., 2004). While subthreshold depression in older adults has received considerable scientific attention, literature on subthreshold anxiety in later life is scarce. However, some evidence suggests that anxiety in later life might mostly be a subthreshold problem. For example, Grenier et al. (2011) showed that the prevalence rate for anxiety problems was $26.2 \%$ when subthreshold anxiety was also considered, compared to $5.6 \%$ for $D S M$-defined anxiety disorders only.

Research suggests that the decreased prevalence of anxiety disorders and relatively high prevalence of subthreshold anxiety in older adults might be a result of common diagnostic instruments and procedures being unsuitable for this age group. Most instruments have been developed for use in younger adult samples, but anxiety symptom expression and experience might be different in older adults (Wolitzky-Taylor et al., 2010). Older adults are more likely to underreport their psychological symptoms (Pachana, 2008) and use other terms in describing them than younger adults (Lenze et al., 2011). Furthermore, due to the chronic nature of anxiety, some have lived with anxiety symptoms for so long that they do not recognize them as problematic any longer (Bryant et al., 2013). Moreover, older adults might less often meet the functional impairment diagnostic criterion than younger adults as a 
result of age-related lower societal demands and expectations. For example, avoidance behavior might be less apparent or problematic in older adults as they typically (are expected to) live less active lives in the first place (Kelley-Moore et al., 2006; Palmer et al., 1997). Lastly, both clinicians and older adults themselves might interpret anxiety symptoms as a normal part of aging (Lenze \& Wetherell, 2009) or a byproduct of cognitive or physical conditions (Jeste et al., 2005; Kogan et al., 2000). All these factors could lead to the structural underdiagnosing of anxiety disorders in later life.

Studies found older adults with subthreshold anxiety to be similar to those with anxiety disorders in terms of limited physical and social activities, decreased well-being, chronic physical problems, comorbid depressive complaints and health services utilization (de Beurs et al., 1999; Grenier et al., 2011). These findings support the notion that common diagnostic instruments do not adequately distinguish between "healthy" and "disordered" anxious older adults and indicate that a narrow focus on (DSMdefined) anxiety disorders hinders a full understanding of later life anxiety. An overview of studies on the prevalence of subthreshold anxiety in older adults and how this compares to the prevalence of anxiety disorders in this population has not yet been published. The current article aims to fill this gap.

The second question this article aims to address is how the prevalence of anxiety disorders and subthreshold anxiety changes throughout later life. It is common for epidemiological studies to only report a prevalence estimate for their total sample of older adults, which often has a wide age range (e.g., $55+$ or $65+$ ). This ignores potential differences between age groups of older adults regarding the nature and prevalence of anxiety, which could arise from biological, psychological, and social changes throughout the later life span. Findings from studies that examined the association between age and the prevalence of later life anxiety are conflicting. Two studies (Byers et al., 2010; Reynolds et al., 2015) that compared four age categories of older adults (55-64, 65-74, $75-84,85+$ ) found a gradual decline with age for social phobia, panic disorder, specific phobia. and posttraumatic stress disorder (PTSD). Their findings differed with regard to generalized anxiety disorder (GAD): Byers et al. found a decline with age for this disorder too, while Reynolds et al. found GAD to be more prevalent in adults aged $85+$ than in those aged $75-84$ years. Another large epidemiological study (Beekman et al., 1998) did not find significant differences between three age groups (55-64, 65-74, 75-85) regarding the prevalence of obsessive compulsive disorder (OCD), GAD, panic disorder, and phobic disorders (a category comprised of social phobia and specific phobia). Lastly, Baladon, et al. (2015) compared three age groups $(65-74,75-84,85+)$ and observed a downward trend with age for the prevalence of agoraphobia, panic disorder, social phobia, specific phobia, GAD, and OCD. However, when controlling for relevant demographic (gender, living situation, employment status) and clinical (somatic comorbidity, perceived social support, perceived disability) factors in a multivariate model, age group was not significantly associated with anxiety disorder prevalence. These conflicting findings might be partly explained by the methodological differences between the studies: They were conducted in different (western) countries, employed different diagnostic instruments, and Beekman and colleagues used DSM-III criteria while the others used DSM-IV criteria.

Combining data from multiple prevalence studies using metaanalysis could lead to more substantial conclusions about age trends in the prevalence of anxiety disorders in later life. It could further provide for a more thorough understanding of the association between age and anxiety in older adults by exploring interactions between age and other relevant study- and participant characteristics (e.g., gender, somatic/cognitive comorbidity, diagnostic instruments/criteria). With regard to subthreshold anxiety, to our knowledge no study has yet directly compared prevalence rates in different age groups of older adults. However, even in the absence of studies reporting separate prevalence rates for different age categories of older adults, a systematic search and integration of scientific literature could allow for a comparison of age groups, because the samples for which prevalence rates are reported might have nonoverlapping age ranges.

Summarizing, the current article has two aims. First, to provide an overview and integration of articles that report prevalence rates for subthreshold anxiety in older adults and to see how these rates compare to those for anxiety disorders. The second aim is to examine the association between age and the prevalence of both later life anxiety disorders and subthreshold anxiety. This way, the current article will contribute to our understanding of later life anxiety, a topic of increasing relevance in light of the unprecedentedly large and steadily growing proportion of older adults worldwide (World Health Organization, 2018).

\section{Method}

\section{Article Selection}

A first search was conducted in April 2018 using four databases (PsycINFO, PUBMED, Cochrane libraries, Web of Science). Reference lists of systematic reviews, meta-analyses, and other relevant articles identified through the database search were also examined. Subsequent searches were conducted in November 2019 and April 2020, limited to articles that were published since the previous search. The full search strings can be found in Appendix A. All articles were screened by authors M.W. and M.S. independently. Inclusion and exclusion decisions were crosschecked and disagreements were resolved by discussion.

Studies were included if they (a) reported (12-month, 6-month, 1-month, current) prevalence rates for; (b) anxiety disorders or subthreshold manifestations of these disorders (panic disorder, agoraphobia, GAD, social anxiety disorder [SAD], OCD, PTSD and specific phobia); (c) in a community sample of adults aged 55 and over; (d) as established with a clinician-administered instrument using $D S M$-criteria (DSM-III, IV or V) or ICD-criteria. Articles had to be written in English or Dutch and published in a peer-reviewed journal to be included.

If a decision on exclusion/inclusion could not be reached due to missing information (e.g., the minimum age of the sample or the diagnostic instrument used was not reported) authors were sent an e-mail with a request for additional information. If authors did not respond after two reminder emails, the study was excluded. Nine authors were sent an e-mail of which four responded with the requested information.

Although DSM-5 does not classify OCD and PTSD as anxiety disorders, we decided on including these disorders in our analyses since most published prevalence studies used DSM-III or DSM-IV criteria (which do classify these two disorders as anxiety disorders) and because feelings of anxiety are a key feature of both disorders. 


\section{Multiplicity}

If more than one article reported prevalence rates for the same type of anxiety disorder and/or subthreshold symptomatology in the same study sample (or subgroups of the sample), we included the article that presented rates for different age groups. If none or all of the articles did this, the article that reported on the largest sample was included. In case of equal sample sizes, the article that provided the most descriptive information about the sample was included.

\section{Coding}

Author M.W. coded all articles. Author M.S. and two master levels clinical psychology students who were trained in the coding system independently coded one third of the articles each. Scorings between raters were cross-checked.

The following information was coded for every sample (if reported also for age-based subsamples): publication year, country of data collection, setting (urban, suburban, rural), primary language(s) of participants, recruitment period, response rate, sample size, proportion of participants with somatic condition(s; plus specification of the condition(s)), proportion with cognitive impairment (plus specification of assessment method), proportion that belongs to an ethnic/cultural minority (plus specification of the group), gender distribution, diagnostic instrument and diagnostic criteria used for classification, whether the instrument was adapted for use in an older population, whether hierarchical diagnostic rules were applied, interview mode, discipline of the interviewer, age range, mean age and standard deviation, and prevalence rates of anxiety disorders/subthreshold anxiety for the sexes combined and (if reported) separately for men and women. A review protocol was submitted to PROSPERO (registration number: CRD42018092953). The protocol can be assessed at https:// www.crd.york.ac.uk/PROSPERO.

\section{Quality Assessment}

As there is no gold standard method for rating the quality of epidemiological studies, we constructed a five-item scale adapted to the needs of this review. We based our rating system on the one used by Volkert, Schulz, Härter, Wlodarczyk, and Andreas (2013) in their meta-analysis on psychiatric disorders in older adults. Each included article was rated by authors M.W. and M.S. or one of the master level students independently on the following criteria: (a) sample size (low risk if sample size was equal or large than 1,000); (b) sample representativeness (low risk for random sampling method); (c) comparability between respondents and nonrespondents (low risk if the response rate was $85 \%$ or more or if a nonresponder analysis indicated no relevant differences between responders and nonresponders); (d) quality of diagnostic assessment method (low risk if psychometric qualities of the instrument were established); (e) quality of prevalence estimates (low risk if obtained from the total sample). Every criterion was scored " 0 " (high risk of bias/ unclear risk of bias) or " 1 " (low risk of bias). Total quality scores were obtained by summing the five item ratings. Differences in quality ratings were resolved through discussion.

\section{Statistical Analyses}

Analyses were conducted using the metafor package (Viechtbauer, 2010) and meta package (Schwarzer, 2007) in the R programming software Version 3.5 (R Core Team, 2018). All analyses were performed separately for each of the seven types of anxiety. Raw prevalence data were transformed to logits to make the proportions normally distributed. Prevalence rates were weighted according to the sample size they were derived from, giving larger studies a greater impact on the pooled effect size. The logits were back-transformed after analysis and reported as percentages.

Pooled prevalence rates were calculated for both the clinical disorders and subthreshold symptomatologies. To compare the prevalence rates of anxiety disorders and subthreshold anxiety, relative risk ratios were calculated and pooled based on the articles that reported prevalence rates for both. The relative risk ratio represented the odds of older adults experiencing subthreshold anxiety compared to the odds of them fulfilling all diagnostic criteria for the anxiety disorder. A risk ratio larger than one indicated the odds of subthreshold anxiety to be higher than the odds of the anxiety disorder, while a risk ratio smaller than one indicated the opposite.

The association between age and the prevalence of anxiety disorders in later life was examined using mixed-effects subgroup analyses to compare prevalence rates for the following age categories: 55-64, 65-74, 75-84 and $85+$. This categorization is common in large epidemiological studies (Neugarten, 1974). Only articles reporting prevalence rates for (sub)sample(s) belonging to (one of) these age categories were included in the subgroup analyses. If the overall $Q$-test for moderation (i.e. the $Q$-between) was statistically significant, the subgroups were tested to examine differences among them. Interactions between age and other variables were tested by examining the $Q$-between value for the interaction term(s). If $Q$-between was significant, it was examined at what levels of the variables the interaction was present.

The Restricted Maximum Likelihood random effects method was used in all analyses. $Q$-tests were conducted to test for heterogeneity across studies. Furthermore, heterogeneity was quantified using $I^{2}$ (values of $25 \%, 50 \%$ and $75 \%$, representing cutoffs for low, medium and high heterogeneity, respectively), which indicates the proportion of between-study variance resulting from heterogeneity rather than from chance. $95 \%$ confidence intervals around $I^{2}$ were calculated. Tests with a $p$ value of less than .05 were interpreted as statistically significant. All $p$ values were two-sided. Outliers were identified by inspecting the externally studentized residuals of the prevalence rates. Rates with values over 2 were considered outliers (Viechtbauer \& Cheung, 2010). To assess the robustness of the results from the main analyses, analyses were repeated without identified outliers.

No funnel plot inspection and formal tests for the detection of publication bias were performed. The results of the articles included in this review are noncomparative and do not contain significance levels and are therefore not interpreted as "negative/ positive" or "undesirable/desirable." This gives the size of the reported prevalence rates little influence in the publication process (Maulik et al., 2011).

\section{Results}

\section{Article Search and Selection}

The database searches yielded 2,209 articles, which dropped to 1,825 after removal of duplicates. Examination of the reference lists of relevant articles identified through the database search resulted in 
an additional 162 articles. In total, titles and abstracts of 1,987 articles were screened. Full-text screening was performed on 728 articles, of which 46 were included in the analyses. For a flowchart of the screening procedure and reasons for article exclusion, see Figure 1. Table 1 and Table 2 list the articles that report prevalence rates for one or more anxiety disorders (all 46 included articles) and types of subthreshold anxiety (six articles), respectively. Articles were assigned an article ID to facilitate clear reporting.

\section{Article Description}

The 46 included articles were published between 1984 and 2019 and reported prevalence rates for adults aged 55+ in 19 different countries across Europe, North and South America, Asia, and Australia. The most commonly used cutoffs to define old(er) were $65 / 66$ years $(n=17)$ and $55 / 56$ years $(n=10)$. The mean age of the sample was presented in 32 articles and

Figure 1

Flowchart of Article Inclusion and Exclusion

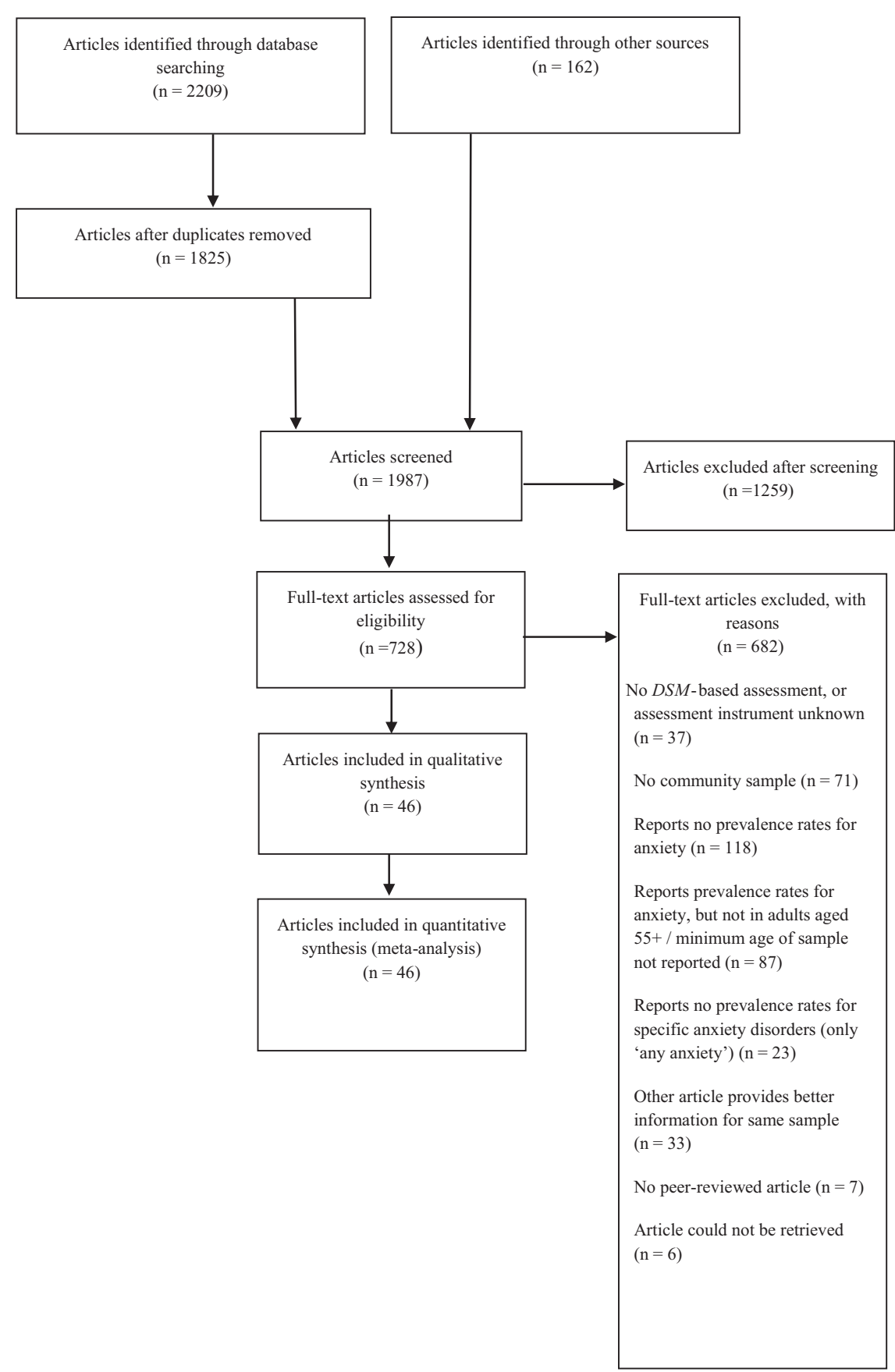




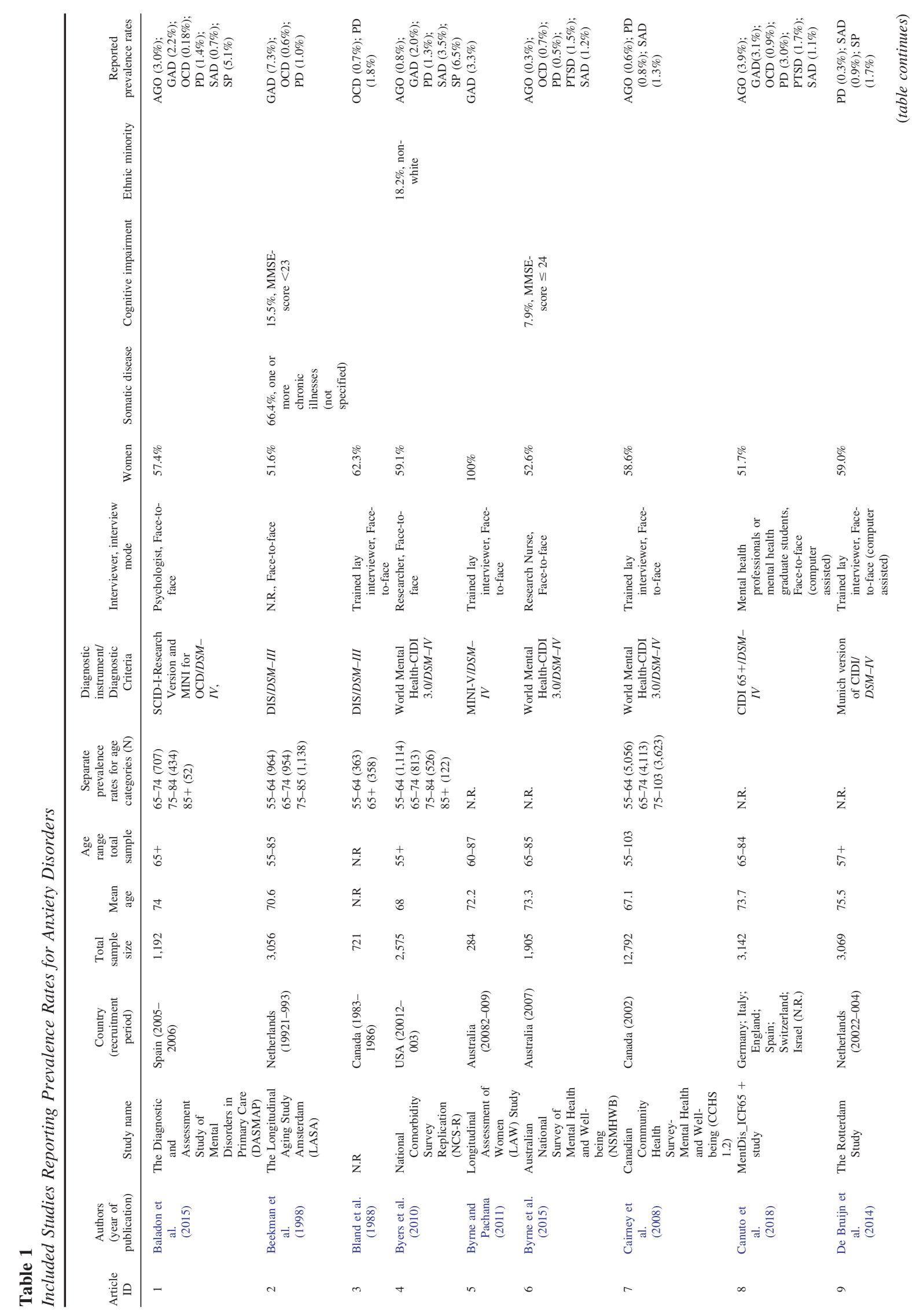




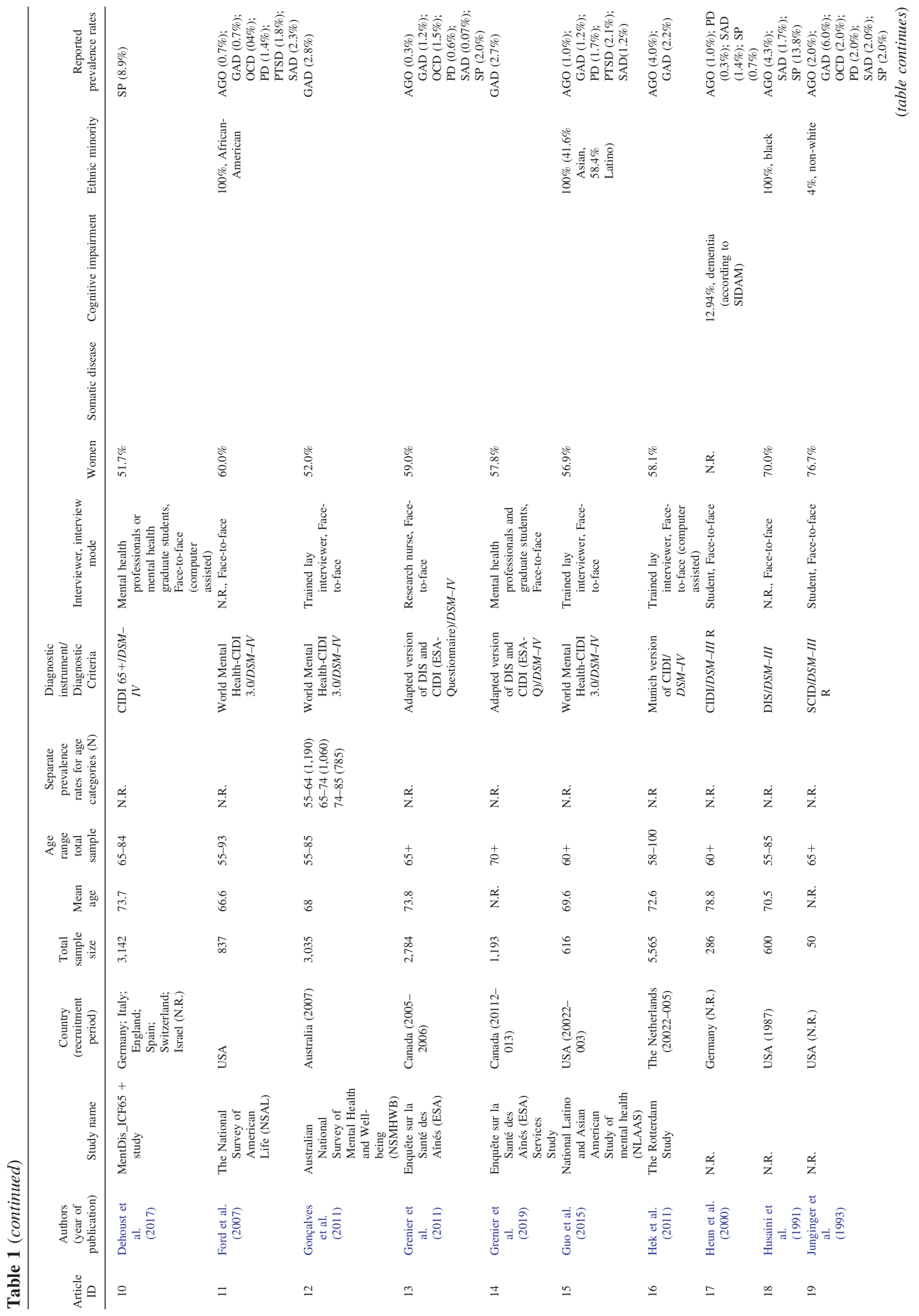




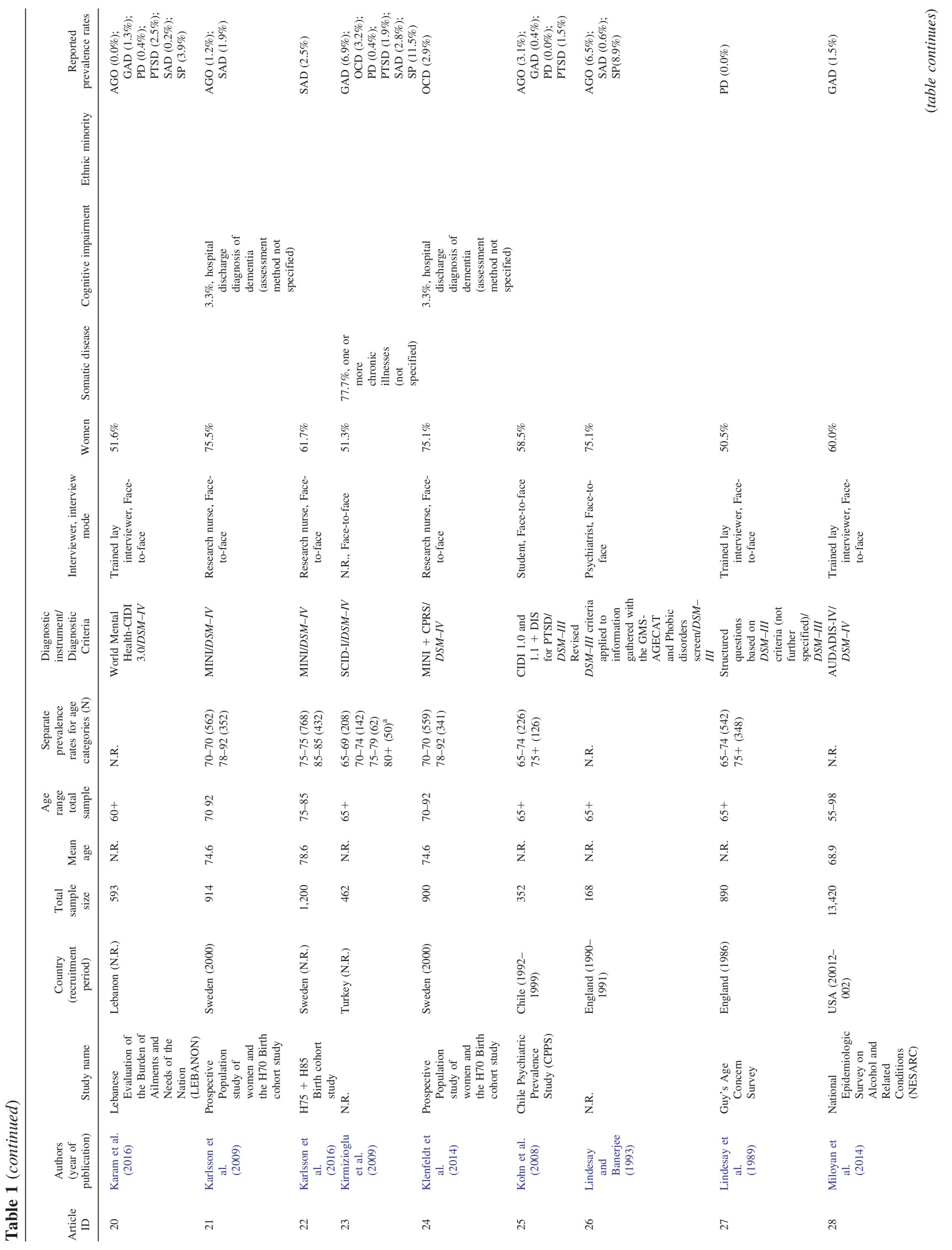




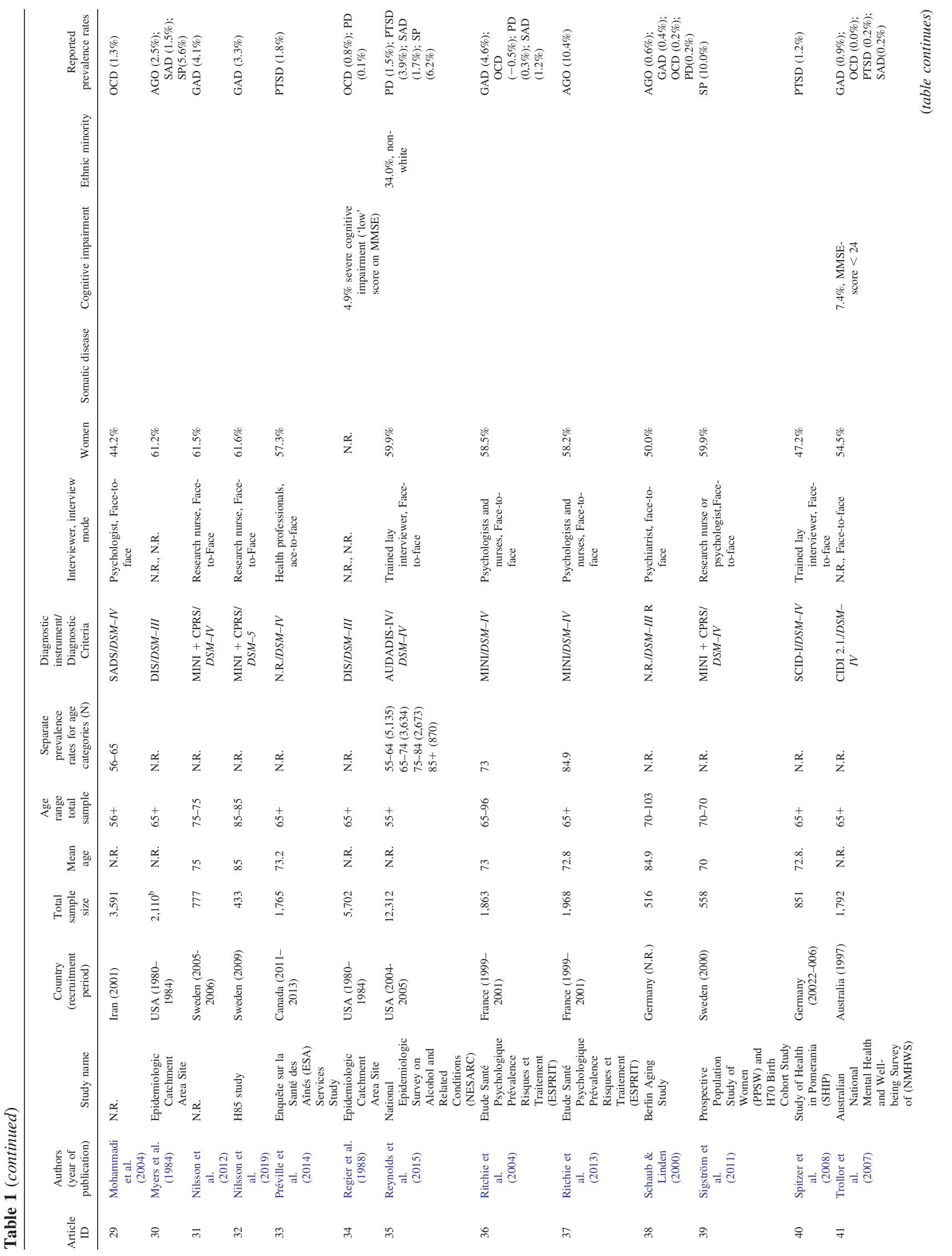




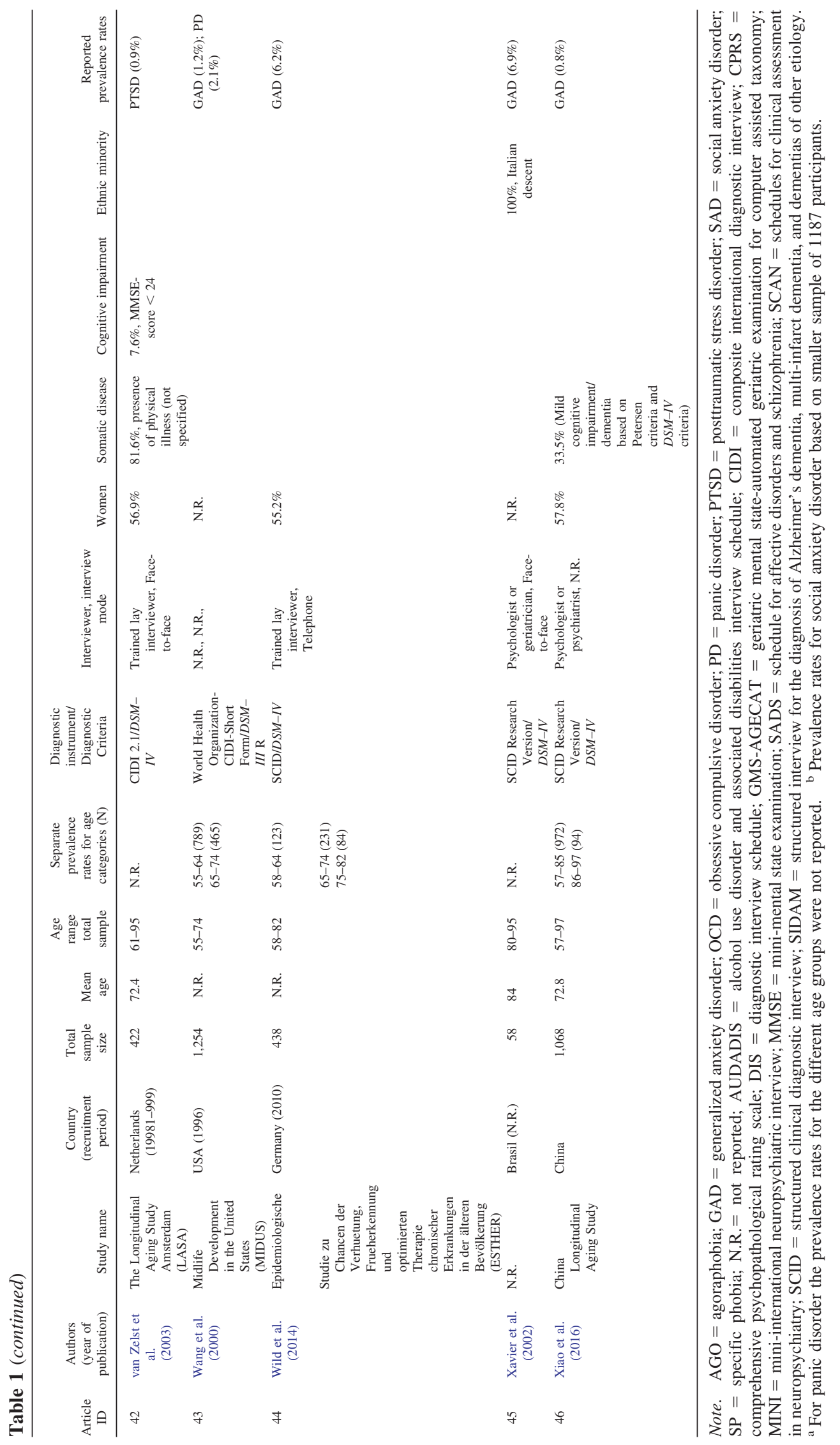


Table 2

Included Studies Reporting Prevalence Rates for Subthreshold Anxiety

\begin{tabular}{|c|c|c|c|c|}
\hline $\begin{array}{l}\text { Article } \\
\text { ID }\end{array}$ & $\begin{array}{c}\text { Authors } \\
\text { (year of publication) }\end{array}$ & $\begin{array}{l}\text { Diagnostic } \\
\text { instrument/diagnostic } \\
\text { criteria }\end{array}$ & Definition & Prevalence \\
\hline 13 & Grenier et al. (2011) & $\begin{array}{l}\text { Adapted version of DIS and } \\
\text { CIDI (ESA-Q)/DSM-IV }\end{array}$ & $\begin{array}{l}\text { AGO, GAD, OCD, PD, SAD, SP: Fulfilling DSM-IV } \\
\text { symptom criteria for a specific anxiety disorder but } \\
\text { reporting no significant disabilities in social } \\
\text { functioning, or reporting symptoms of anxiety (e.g., } \\
\text { anticipations, sweating, palpitations) not meeting } \\
\text { symptom criteria for a disorder }\end{array}$ & $\begin{array}{l}\text { AGO }(4.2 \%) \\
\text { GAD }(3.0 \%) \\
\text { OCD }(1.6 \%) \\
\text { PD }(2.6 \%) \\
\text { SAD }(1.3 \%) \\
\text { SP }(7.8 \%)\end{array}$ \\
\hline 17 & Heun et al. (2000) & CIDI/DSM-III R & $\begin{array}{l}\text { AGO: Unreasonable fear in places/situations from } \\
\text { which it is difficult to leave; lack of avoidance or } \\
\text { of symptoms of anxiety. } \\
\text { PD: Presence of acute unexpected anxiety attacks, } \\
\text { one to four physical symptoms. } \\
\text { SAD: Persistent fear of situations in which the person } \\
\text { is exposed to social interactions; lack of avoidance } \\
\text { or social consequences. } \\
\text { SP: Persistent fear of circumscribed stimulus, lack of } \\
\text { avoidance or consequences. }\end{array}$ & $\begin{array}{l}\text { AGO }(0.7 \%) \\
\text { PD }(1.7 \%) \\
\text { SAD }(1.4 \%) \\
\text { SP }(8.4 \%)\end{array}$ \\
\hline 22 & $\begin{array}{l}\text { Karlsson et al. } \\
\text { (2009) }\end{array}$ & $\mathrm{MINI} / D S M-I V$ & $\begin{array}{l}\text { SAD: Persistent fear of situations in which the person } \\
\text { is exposed to social interactions (criterion A is } \\
\text { fulfilled), The situations are avoided or endured } \\
\text { with intense anxiety or distress (criterion D is } \\
\text { fulfilled). The fear does not worsen functioning in } \\
\text { social situations, nor does it cause considerable } \\
\text { distress (criterion E is not fulfilled). }\end{array}$ & SAD $(11.5 \%)$ \\
\hline 28 & $\begin{array}{l}\text { Miloyan et al. } \\
\text { (2014) }\end{array}$ & AUDADIS-IV/DSM-IV & $\begin{array}{l}\text { GAD: six or more months of worry, tension, or } \\
\text { nervousness, without meeting criteria for a } D S M \\
\text { anxiety disorder. }\end{array}$ & GAD $(7.2 \%)$ \\
\hline 33 & Préville et al. (2014) & N.R./DSM-IV & $\begin{array}{l}\text { PTSD: At least one symptom from each of the three } \\
D S M-I V \text { symptom clusters for the last six months, } \\
\text { with or without the presence of impairment in } \\
\text { social functioning. }\end{array}$ & PTSD (1.8\%) \\
\hline 42 & $\begin{array}{l}\text { van Zelst et al. } \\
\quad(2003)\end{array}$ & CIDI 2.1/DSM-IV & $\begin{array}{l}\text { PTSD: A Self-Rating Inventory for Posttraumatic } \\
\text { Stress Disorder (SRIP; scale is based on DSM-IV } \\
\text { criteria) score of } 39 \text { or higher, without meeting all } \\
D S M-I V \text { criteria. }\end{array}$ & PTSD (13.1\%) \\
\hline
\end{tabular}

Note. $\mathrm{AGO}=$ agoraphobia; $\mathrm{GAD}=$ generalized anxiety disorder; $\mathrm{OCD}=$ obsessive compulsive disorder; $\mathrm{PD}=$ panic disorder; $\mathrm{PTSD}=$ posttraumatic stress disorder; $\mathrm{SAD}=$ social anxiety disorder; $\mathrm{SP}=$ specific phobia; N.R. = not reported; AUDADIS = alcohol use disorder and associated disabilities interview schedule; CIDI = composite international diagnostic interview; DIS $=$ diagnostic interview schedule; MINI $=$ mini-international neuropsychiatric interview; SCAN $=$ schedules for clinical assessment in neuropsychiatry.

ranged from 66.6 to 85.0 years, with a median of 72.9. Information on the gender composition of the sample was reported in 42 articles. Reported proportions of women ranged from $44.2 \%$ to $100 \%$, with a median of $58.5 \%$. The most frequently used diagnostic instruments were the Composite International Diagnostic Interview (CIDI, $n=18$; World Health Organization, 1990), the Mini-international Neuropsychiatric Interview (MINI, $n=8$; Sheehan et al., 1998) and the Structured Clinical Interview for DSM Axis I Disorders (SCID, $n=7$; First et al., 1995). DSM-IV criteria were used in 33 articles, DSM-III criteria in 12 and $D S M-5$ criteria in one. Twenty-five articles reported prevalence rates for GAD, 22 for panic disorder, 21 for SAD, 19 for agoraphobia, 14 for specific phobia, 15 for OCD, and 12 for PTSD. Considering subthreshold anxiety, three articles reported prevalence rates for subthreshold social anxiety, two articles for subthreshold agoraphobia, generalized anxiety, specific phobia, and posttraumatic stress and one article reported rates for subthreshold OCD. Subthreshold anxiety was operationalized differently across studies (see Table 2).

\section{Quality Assessment}

Thirteen articles had a total quality score of five, indicating that their risk of bias was low for all five criteria. Twenty articles had a total score of four, 11 of three and two articles of two. No articles had a total score of one or zero points. The most common risk of bias was the small sample size: 22 articles (47.8\%) reported on sample sizes smaller than 1,000. Comparability of nonresponders and responders was not sufficient or not investigated in 18 articles $(39.1 \%)$. Quality of the diagnostic assessment method used was unknown for four articles: These articles reported to have used a $D S M$-based assessment method but did not report a specific instrument. One article did not use a random sampling method. One article did not report prevalence rates based on the total study sample but instead used subsample based extrapolation.

\section{Prevalence of Subthreshold Anxiety and Anxiety Disorders}

Table 3 shows the results of the meta-analyses on the prevalence of anxiety disorders and subthreshold anxiety. The following 


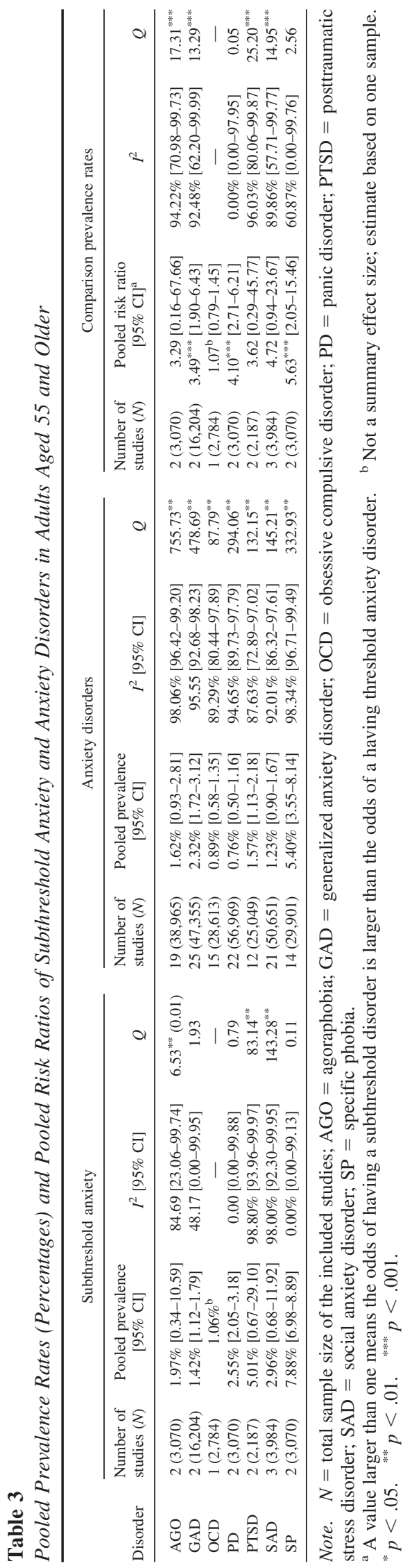

pooled prevalence rates were found for the different types of subthreshold anxiety: 7.88\% [6.98-8.89] for specific phobia; $5.01 \%$ [0.67-29.10] for posttraumatic stress; $2.96 \%$ [0.68-11.92] for social anxiety; $2.55 \%[2.05-3.18]$ for panic; $1.97 \%$ [0.34-10.59] for agoraphobia; $1.42 \%$ [1.12-1.79] for generalized anxiety. For subthreshold OCD, no pooled prevalence rate could be calculated, because only one study reported a prevalence rate for it $(1.06 \%)$. Nonsignificant $Q$-values and $I^{2}$ s below $50 \%$ (but with wide confidence intervals) indicated that reported prevalence rates for subthreshold generalized anxiety, panic and specific phobia were relatively homogeneous. Prevalence rates for subthreshold agoraphobia, PTSD, and social anxiety were highly heterogeneous (i.e., statistically significant $Q$-values and $I^{2}$ s over $75 \%$ ). The following pooled prevalence rates were found for anxiety disorders: $5.40 \%$ [3.55-8.14] for specific phobia; $2.32 \%$ [1.72-3.12] for GAD; $1.62 \%$ [0.93-2.81] for agoraphobia; $1.57 \%$ [1.13-2.18] for PTSD; $1.23 \%$ [0.90-1.67] for SAD; $0.89 \%$ [0.58-1.35] for OCD; $0.76 \%$ [0.50-1.16] for panic disorder. For all anxiety disorders, reported prevalence rates were highly heterogeneous as indicated by significant $Q$-values and large $I^{2}$ s. With the exception of generalized anxiety, all pooled estimates were higher for subthreshold symptomatology than for the clinical disorder. However, panic was the only type of anxiety for which the confidence interval of the two pooled prevalence rates did not overlap.

The six articles that reported prevalence rates for subthreshold anxiety also reported prevalence rates for anxiety disorders in their samples. For these samples, the prevalence rates for subthreshold anxiety and the clinical disorder were compared using risk ratios. These meta-analyses resulted in pooled risk ratios higher than one for every type of anxiety, which indicates that the odds of older adults experiencing subthreshold symptomatology is higher than the odds of older adults having an anxiety disorder. For generalized anxiety $(\mathrm{RR}=3.49[1.90-6.43], p<.001)$, panic $(\mathrm{RR}=4.10$ $[2.71-6.21], p<.001)$, and specific phobia $(\mathrm{RR}=5.63$ [2.05-15.46], $p<.001)$, the pooled risk ratios were statistically significant. With the exception of panic $\left(I^{2}=0.00 \%\right.$ [0.00-97.95]); $Q=0.05$ and specific phobia $\left(I^{2}=60.87 \%\right.$ [00-99.76]); $Q=2.56, I^{2}$ estimates for the pooled risk ratios were larger than $75 \%$ and $Q$-values were significant, indicating substantial unexplained heterogeneity between the risk ratios.

\section{Prevalence Rates in Different Age Categories}

Appendix B lists the studies that reported prevalence rates for anxiety disorders in one or more of the specified age categories (55-64, 65-74, 75-84, 85+). See Table 4 for the results of the subgroup analyses comparing prevalence rates of anxiety disorders between these age groups.

The test of moderation (Q-between) was significant for specific phobia $(Q=10.31, p=.02)$ and $\operatorname{PTSD}(Q=60.82, p<.0001)$. Regarding specific phobia, both the 75-84 and 85+ group had lower pooled prevalence rates than the 55-64 (75-84: $z=2.36$, $p=.02 ; 85+: z=2.48, p=.01)$ and $65-74$ groups $(75-84: z=$ $2.03, p=.04 ; 85+: z=2.16, p=.01)$. Regarding PTSD, the prevalence estimate in the 55-64 group was significantly higher than estimates for all three other age groups $(65-74: z=6.00, p<$ $.0001 ; 75-84: z=4.91, p<.0001 ; 85+: z=4.57, p<.0001)$. Furthermore, the estimate for the $85+$ sample was lower than the 


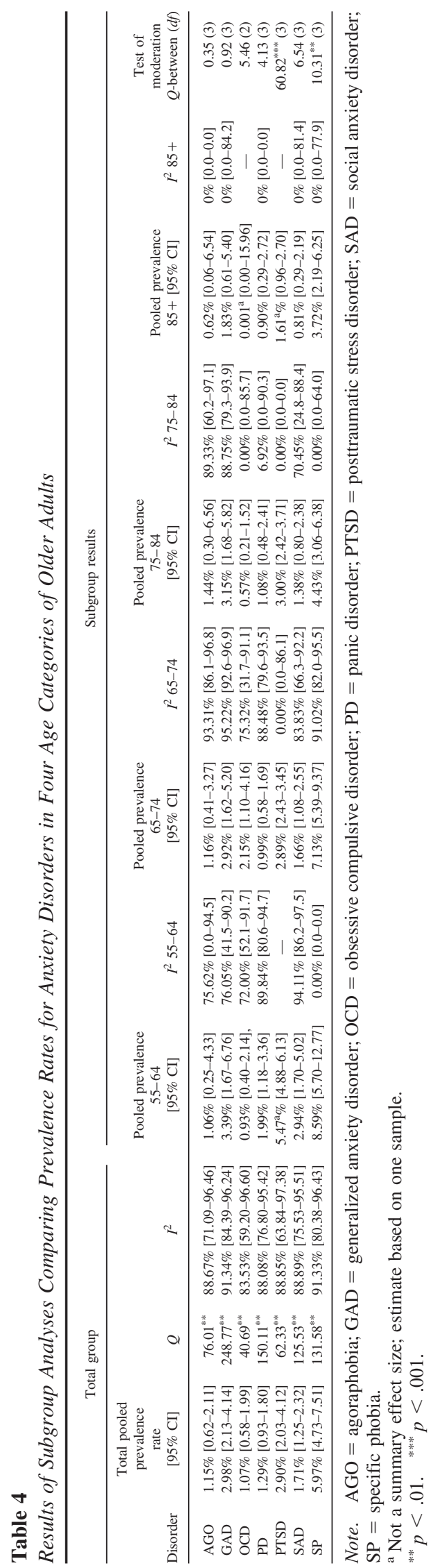

pooled estimates for the $65-74(z=2.11, p=.04)$ and 75-84 $(z=$ $2.18, p=.03)$ groups. No other significant differences between age groups were found. For all seven anxiety disorders, subgroup analyses showed the $85+$ group to have the lowest prevalence rate (although not significantly lower in most cases). No recurring pattern was apparent in the pooled prevalence rates for the other three age groups.

None of the subgroup analyses resulted in four groups with homogeneous prevalence rates. For all $85+$ groups, $I^{2}$ estimates of $0.00 \%$ indicated low heterogeneity, but confidence intervals around the estimates were wide, ranging from $0 \%$ to values over $75 \% . I^{2}$ estimates were also low (but with wide confidence intervals) for the 75-84 groups in the analyses on OCD, panic disorder, PTSD and specific phobia, the 65-74 group for PTSD, and the 55-64 group for specific phobia.

The association between age and the prevalence of subthreshold anxiety could not be examined because no article reported prevalence rates for subthreshold anxiety in different age categories, nor did the samples for which prevalence rates were reported fall into different prespecified age categories.

\section{Interactions of Age and Other Participant/Study Characteristics}

Separate prevalence rates for men and women in different age categories were available for GAD (65-74 and 75-84), OCD (all four age categories), panic disorder $(55-64,65-74,85+)$, and SAD $(65-74,75-84,85+)$. For none of these disorders, a significant interaction between age and sex was found (GAD: $Q(1)=$ 0.002, $p=.96$; OCD: $Q(3)=1.67, p=.64$; panic disorder: $Q(2)=2.59, p=.28$; SAD: $Q(2)=0.05, p=.98)$. Interactions between age and the participant variables of physical impairment, cognitive impairment, and ethnic/cultural background could not be examined because no article provided information about these variables for one (or more) of the specified age categories.

The interaction between $D S M$-criteria (III vs. IV) and age could be examined for GAD (55-64, 65-74, 75-84), OCD (55-64, $65-74,75-84)$, and panic disorder $(55-64,65-74,85+)$. Interaction terms were nonsignificant for all three disorders (GAD: $Q(2)=1.55, p=.46$; OCD: $Q(2)=3.63, p=.16$; panic disorder: $Q(2)=0.84, p=.66$ ). Interactions between age and the use of hierarchical diagnostical rules and use of diagnostic instrument specifically adapted to older adults could not be investigated because these variables were not reported on in any of the articles that presented prevalence estimates for (one or more of) the specified age categories. Interactions with interview mode, interviewer discipline, study country, and study setting could also not be investigated because there was no variation in these variables among the age-specific samples.

\section{Outliers}

Outlying values were identified when pooling prevalence rates for agoraphobia (article ID 26), OCD (article IDs 23, 41), PTSD (article IDs 35, 41), panic disorder (article IDs 34, 43), SAD (article IDs 13, 41), and specific phobia (article ID 17). Regarding the pooled prevalence rates for the prespecified age categories, outliers were identified in the 55-64 group for GAD (article ID 43 ), the 65-74 group for OCD (article ID 1), the 55-64 and 65-74 
group for panic disorder (article ID 43 for both groups), and the 55-64 (article ID 4) and 75-84 (article ID 22) group for SAD. The articles that reported the outlying values were inspected, but no factors were identified that could have structurally influenced the results, so it was not justified to exclude these articles from the main analyses.

Sensitivity analyses without the outliers resulted in the following pooled prevalence rates for anxiety disorders, which were only marginally different from the pooled estimates in the main analyses: $1.43 \%$ [0.85-2.39] for agoraphobia; $0.88 \%$ [0.58-1.35] for OCD; $1.67 \%$ [1.44-1.92] for PTSD; 0.81\% [0.57-1.14] for panic disorder; $1.48 \%$ [1.18-1.85] for SAD; 5.94\% [4.02-8.69] for specific phobia. For PTSD, heterogeneity between studies decreased after removing the outliers $\left(Q=4.23, p=.90, I^{2}=0.00\right.$ [0.00-51.66]). For all other disorders heterogeneity was still large (i.e. $p$ values for $Q<.01$ and $I^{2}>80 \%$ ).

See Appendix $C$ for the results of the sensitivity subgroup analyses without outliers. For GAD, panic disorder, and SAD, analyses without outliers had comparable results to the main analyses and did not show significant differences between the age groups. For OCD, results from the analysis without the outlier differed from those from the main analysis: The pooled prevalence rate for the $65-74$ group of $2.58 \%$ [1.52-4.37] was significantly higher than those for the 55-64 $(1.05 \%$ [0.53-2.04], $z=2.08, p=.04)$ and 75-84 (0.55\% [0.23-1.31], $z=$ $2.99, p=.002$ ) groups.

\section{Discussion}

This article used a systematic review and meta-analyses to examine how prevalence rates of subthreshold anxiety compare to rates for anxiety disorders and if prevalence rates for later life anxiety differ between age groups of older adults.

\section{Main Findings}

Statistical comparison of prevalence rates, using pooled risk ratios, showed that for generalized anxiety, panic, and specific phobia, subthreshold symptomatology was significantly more prevalent than the corresponding clinical disorder. For the other types of anxiety, pooled risk ratios showed prevalence rates for subthreshold anxiety and anxiety disorders to not be significantly different. Although the results from this meta-analysis do not allow for strong conclusions due to the small number of included samples and large heterogeneity in the estimates, they do suggest that subthreshold anxiety is at least similarly prevalent to anxiety disorders. The combination of this finding with earlier studies showing subthreshold anxiety in older adults to be associated with decreased well-being, social functioning, and physical health (de Beurs et al., 1999; Grenier et al., 2011) indicates that subthreshold anxiety in later life is both a prevalent and clinically relevant phenomenon for which adequate detection and treatment is required. However, for a comprehensive understanding of subthreshold anxiety in older adults, more methodologically rigorous studies are needed. First and foremost, researchers and clinicians should work toward comprehensive definitions of the different types of subthreshold anxiety that can be used across studies. All studies on subthreshold anxiety included in this review used different definitions, which probably largely explains the substantial heterogeneity.

Regarding age trends in prevalence rates, for most anxiety disorders (agoraphobia, GAD, OCD, panic disorder, and SAD) pooled prevalence rates did not significantly differ between age groups of older adults. The lack of statistical significance may be due to the low statistical power of the analyses caused by the small number of samples in the subgroups. Pooled prevalence rates for specific phobia and PTSD were found to differ significantly between age groups. For specific phobia, the 75-84 and 85+ groups had lower prevalence rates than both the 55-64 and 65-74 group. One explanation for the lower rates of specific phobia in the oldest groups is that diagnostic instruments do not adequately address fears typical to these age groups, most notably fear of falling. Prevalence estimates for fear of falling in older adults range between $21 \%$ and $85 \%$ and increase with age (Scheffer et al., 2008). Other specific fears that may be relatively common in the oldest groups are a fear of crime/aggression and the use of modern technology (Marquié et al., 2002; Mohlman et al., 2020; Mohlman et al., 2012). If diagnostic instruments would explicitly assess such age-related fears, prevalence estimates for specific phobia might be higher in the oldest groups. For PTSD, the prevalence rate for the 55-64 group was higher than that for all other age groups, while the $85+$ group had a significantly lower rate than the other groups. It could be speculated that an age-related decrease in PTSD prevalence partly reflects the natural course of recovery from trauma. Assuming that most traumatic events happen when people are younger adults, lower PTSD rates in the oldest adults could be reflective of a longer recovery time since the traumatic event (Creamer \& Parslow, 2008; Pless Kaiser et al., 2019).

Other explanations for an age-related decrease of specific phobia and PTSD are not disorder specific and could also account for the finding that prevalence rates were lowest in the $85+$ group for all anxiety disorders (although not significantly lower in most cases). First, lower rates in the oldest groups of older adults could reflect a survivor effect of older adults without anxiety generally living longer than their anxious peers (Pratt et al., 2016). Furthermore, it could be argued that age-related obstacles in adequately assessing anxiety disorders (i.e. overlap of anxiety symptoms and physical/cognitive conditions, underestimation of functional impairment due to lower societal expectations) increase with age and are therefore strongest in the oldest groups, leading to structural underdiagnosing. Third, community samples might not adequately represent the oldest adults, who are increasingly characterized by physical and neurodegenerative diseases and associated institutional care (World Health Organization, 2018). As community samples typically do not include institutionalized people, they might seriously underestimate the prevalence of anxiety disorders in the oldest groups. A systematic review of 18 studies on older adults in nursing homes and residential care facilities (mean age of the study samples ranged from 74.9 to 86.2 years) indeed concluded that anxiety disorders appear to be more prevalent among old age care residents than community-dwelling older adults (Creighton et al., 2016).

Sensitivity subgroup analyses without outliers replicated the results from the main analyses for most disorders, but for OCD, it resulted in a significant difference in pooled prevalence rates for OCD between age groups, with higher rates being reported for adults aged 65-74 than for those aged 55-64 and 75-84. More research into the prevalence of later life OCD is required to see if this finding replicates and, if so, to examine how a prevalence peak in the 65-74 years old could be explained. 
For none of the anxiety disorders subgroup analyses resulted in four groups of homogeneous prevalence estimates, although for the $85+$ and 75-84 groups heterogeneity was low in most cases. It is understandable that a categorization of samples based solely on their age range did not explain all heterogeneity in prevalence rates, as variation in reported rates is most likely caused by a combination of multiple study and participant characteristics. Therefore, the current study set out to also explore interactions between age and other methodological/participant factors. Unfortunately, due to the limited amount of reported information in the included articles, interactions could not be explored extensively. The available information only allowed for the examination of interactions between age on the one hand and sex and DSM-criteria on the other. These interactions were nonsignificant, which could be due to the lack of statistical power from the small number of included samples. To comprehensively investigate the association between age and the prevalence of anxiety disorders in later life, studies in older adults should consistently report descriptive information for different age groups within their sample.

\section{Limitations}

This study has several limitations. First, the small number of samples that could be used in answering our research questions influenced the confidence intervals and limits the statistical power of the analyses and generalizability of the results. For most types of anxiety, only two articles reported rates for both subthreshold symptomatology and the corresponding clinical disorder. Furthermore, no article reported prevalence rates for subthreshold anxiety in different age groups of older adults. For anxiety disorders, the age-based subgroups also consisted of a small number of samples, with the largest subgroup being comprised of eight samples. Importantly, only five articles reported prevalence rates for the $85+$ group, which were mostly obtained in small samples. Large-scale epidemiological studies focused on the $85+$ segment are required, especially since in many countries the oldest-old are the fastest growing part of the total population (World Health Organization, 2018).

A second limitation concerns the subgroup analyses, in which subgroups were created based solely on the age of participants in the samples. This approach does not account for cohort effects, while these are likely to have also contributed to differences in reported prevalence estimates, as the included articles were published between 1984 and 2019. For a comprehensive understanding of the relation between age and prevalence rates of later life anxiety, age and cohort effects should be separated.

Third, we only included community samples, which limits the generalizability of the findings, especially with regard to the oldestold.

Last, while four electronic databases were screened and an additional hand-search was conducted, it is possible that some relevant publications have not been included in the review and meta-analyses. For instance, publications in languages other than Dutch and English and non-peer-reviewed articles were not included.

\section{Conclusion and Implications}

This article provided an overview and integration of articles reporting prevalence rates for anxiety disorders and subthreshold anxiety in older adults and highlighted gaps and shortcomings in the literature. The findings from the meta-analyses suggest that subthreshold anxiety is similarly or more prevalent than anxiety disorders, although the small number of included samples and large heterogeneity between them precludes firm conclusions. As the currently available evidence suggests that subthreshold anxiety in older adults is both prevalent and clinically relevant, it should be studied more extensively. A first step is for researchers to work toward comprehensive definitions and operationalizations of subthreshold anxiety that can be used across studies.

Regarding the association between the prevalence of later life anxiety disorders and age, the subgroup analyses do not allow for strong conclusions due to the small number of included samples. Results suggest that specific phobia is more common in older adults aged 55-74 than in those aged 75 years and older. Furthermore, PTSD seems to be most prevalent in adults aged 55-64 and least prevalent in the $85+$ group. We recommend future studies in older adults to consistently report information for different age categories. Furthermore, longitudinal studies following different cohorts of older adults are needed for a better understanding of the association between age and the prevalence of anxiety in later life. Such studies are time intensive and financially demanding, but as the number of older adults is steadily growing worldwide, highquality studies into how people progress throughout later life are invaluable.

\section{References}

Baladon, L., Fernandez, A., Rubio-Valera, M., Cuevas-Esteban, J., Palao, D. J., Bellon, J. A., \& Serrano-Blanco, A. (2015). Prevalence of mental disorders in non-demented elderly people in primary care. International Psychogeriatrics, 27(5), 757-768. https://doi.org/10.1017/s1041610 214002841

Beekman, A. T. F., Bremmer, M. A., Deeg, D. J. H., van Balkom, A. J. L. M., Smit, J., de Beurs, E., van Dyke, R., \& van Tilburg, W. (1998). Anxiety disorders in later life: A report from the longitudinal aging study Amsterdam. International Journal of Geriatric Psychiatry, 13(10), 717-726. https://doi.org/10.1002/(SICI)1099-1166(1998100)13: $10<717::$ AID-GPS857>3.0.CO;2-M

Bland, R. C., Orn, H., \& Newman, S. C. (1988). Lifetime prevalence of psychiatric disorders in Edmonton. Acta Psychiatrica Scandinavica, 77(S338), 24-32. https://doi.org/10.1111/j.1600-0447.1988.tb08544.x

Bryant, C., Mohlman, J., Gum, A., Stanley, M., Beekman, A. T. F., Wetherell, J. L., Thorp, S. R., Flint, A. J. F. R. C. P. C. F. R. A. N. Z. C. P., \& Lenze, E. J. (2013). Anxiety disorders in older adults: Looking to DSM5 and beyond. The American Journal of Geriatric Psychiatry, 21(9), 872-876. https://doi.org/10.1016/j.jagp.2013.01.011

Byers, A. L., Yaffe, K., Covinsky, K. E., Friedman, M. B., \& Bruce, M. L. (2010). High occurrence of mood and anxiety disorders among older adults. Archives of General Psychiatry, 67(5), 489-496. https://doi.org/ 10.1001/archgenpsychiatry.2010.35

Byrne, G. J., \& Pachana, N. A. (2011). Development and validation of a short form of the geriatric anxiety inventory-The GAI-SF. International Psychogeriatrics, 23(1), 125-131. https://doi.org/10.1017/ S1041610210001237

Byrne, G. J., Steele, S. J., \& Pachana, N. A. (2015). Delusion-like experiences in older people with anxiety disorders. International Psychogeriatrics, 27(7), 1191-1196. https://doi.org/10.1017/S10416102 15000113

Cairney, J., Corna, L. M., Veldhuizen, S., Herrmann, N., \& Streiner, D. L. (2008). Comorbid depression and anxiety in later life: Patterns of association, subjective well-being, and impairment. The American Journal of 
Geriatric Psychiatry, 16(3), 201-208. https://doi.org/10.1097/01.JGP $.0000300627 .93523 . c 8$

Canuto, A., Weber, K., Baertschi, M., Andreas, S., Volkert, J., Dehoust, M. C., Sehner, S., Suling, A., Wegscheider, K., Ausin, B., Crawford, M. J., Da Ronch, C., Grassi, L., Hershkovitz, Y., Munoz, M., Quirk, A., Rotenstein, O., Santos-Olmo, A. B., Shalev, A., . . Härter, M. (2018). Anxiety disorders in old age: Psychiatric comorbidities, quality of life, and prevalence according to age, gender, and country. The American Journal of Geriatric Psychiatry, 26(2), 174-185. https://doi.org/10 .1016/j.jagp.2017.08.015

Creamer, M., \& Parslow, R. (2008). Trauma exposure and posttraumatic stress disorder in the elderly: A community prevalence study. The American Journal of Geriatric Psychiatry, 16(10), 853-856. https://doi .org/10.1097/01.JGP.0000310785.36837.85

Creighton, A. S., Davison, T. E., \& Kissane, D. W. (2016). The prevalence of anxiety among older adults in nursing homes and other residential aged care facilities: A systematic review. International Journal of $\mathrm{Ge}$ riatric Psychiatry, 31(2), 555-566. https://doi.org/10.1002/gps.4378

de Beurs, E., Beekman, A. T. F., van Balkom, A. J. L. M., Deeg, D. J. H., van Dyck, R., \& van Tilburg, W. (1999). Consequences of anxiety in older persons: Its effect on disability, well-being and use of health services. Psychological Medicine, 29(3), 583-593. https://doi.org/10 $.1017 /$ S0033291799008351

de Bruijn, R. F., Direk, N., Mirza, S. S., Hofman, A., Koudstaal, P. J., Tiemeier, H., \& Ikram, M. A. (2014). Anxiety is not associated with the risk of dementia or cognitive decline: The Rotterdam study. The American Journal of Geriatric Psychiatry, 22(12), 1382-1390. https://doi.org/ 10.1016/j.jagp.2014.03.001

Dehoust, M. C., Schulz, H., Härter, M., Volkert, J., Sehner, S., Drabik, A., Wegscheider, K., Canuto, A., Weber, K., Crawford, M., Quirk, A., Grassi, L., DaRonch, C., Munoz, M., Ausin, B., Santos-Olmo, A., Shalev, A., Rotenstein, O., Hershkowitz, Y., . . Andreas, S. (2017). Prevalence and correlates of somatoform disorders in the elderly: Results of a European study. International Journal of Methods in Psychiatric Research, 26(1), e1550. https://doi.org/10.1002/mpr.1550

First, M. B., Spitzer, R. L., Gibbon, M., \& Williams, J. B. W. (1995). Structured clinical interview for DSM-IV axis I disorders. American Psychiatric Press.

Ford, B. C., Bullard, K. M., Taylor, R. J., Toler, A. K., Neighbors, H. W., \& Jackson, J. (2007). Lifetime and 12-month prevalence of diagnostic and statistical manual of mental disorders, fourth edition, among older African Americans: Findings from the national survey of American life. The American Journal of Geriatric Psychiatry, 15(8), 652-659. https:// doi.org/10.1097/JGP.0b013e3180437d9e

Gonçalves, D. C., Pachana, N. A., \& Byrne, G. J. (2011). Prevalence and correlates of generalized anxiety disorder among older adults in the Australian national survey of mental health and well-being. Journal of Affective Disorders, 132(1-2), 223-230. https://doi.org/10.1016/j.jad .2011 .02 .023

Grenier, S., Desjardins, F., Raymond, B., Payette, C., Rioux, M., Landreville, P., Gosselin, P., Richer, M.-J., Gunther, B., Fournel, M., \& Vasiliadis, M. (2019). Six-month prevalence and correlates of generalized anxiety disorder among primary care patients aged 70 years and above: Results from the ESA-services study. International Journal of Geriatric Psychiatry, 34(2), 315-323. https://doi.org/10.1002/gps.5023

Grenier, S., Préville, M., Boyer, R., O’Connor, K., Béland, S., Potvin, O., Hudon, C., Brassard, J., \& the Scientific Committee of the ESA Study. (2011). The impact of DSM-IV symptom and clinical significance criteria on the prevalence estimates of subthreshold and threshold anxiety in the older adult population. The American Journal of Geriatric Psychiatry, 19(4), 316-326. https://doi.org/10.1097/JGP.0b013e3181ff416c

Gum, A. M., King-Kallimanis, B., \& Kohn, R. (2009). Prevalence of mood, anxiety, and substance- abuse disorders for older Americans in the national comorbidity survey-replication. The American Journal of Ge- riatric Psychiatry, 17(9), 769-781. https://doi.org/10.1097/JGP .0b013e3181ad4f5a

Guo, M., Li, S., Liu, J., \& Sun, F. (2015). Family relations, social connections, and mental health among Latino and Asian older adults. Research on Aging, 37(2), 123-147. https://doi.org/10.1177/ 0164027514523298

Hek, K., Tiemeier, H., Newson, R. S., Luijendijk, H. J., Hofman, A., \& Mulder, C. L. (2011). Anxiety disorders and comorbid depression in community dwelling older adults. International Journal of Methods in Psychiatric Research, 20(3), 157-168. https://doi.org/10.1002/mpr.344

Heun, R., Papassotiropoulos, A., \& Ptok, U. (2000). Subthreshold depressive and anxiety disorders in the elderly. European Psychiatry, 15(3), 173-182. https://doi.org/10.1016/S0924-9338(00)00228-5

Husaini, B. A., Moore, S. T., \& Castor, R. S. (1991). Social and psychological well-being of Black elderly living in high-rises for the elderly. Journal of Gerontological Social Work, 16(3-4), 57-78. https://doi.org/ 10.1300/J083v16n03_06

Jeste, D. V., Blazer, D. G., \& First, M. (2005). Aging-related diagnostic variations: Need for diagnostic criteria appropriate for elderly psychiatric patients. Biological Psychiatry, 58(4), 265-271. https://doi.org/10 .1016/j.biopsych.2005.02.004

Junginger, J., Phelan, E., Cherry, K., \& Levy, J. (1993). Prevalence of psychopathology in elderly persons in nursing homes and in the community. Hospital \& Community Psychiatry, 44(4), 381-383. https://doi .org/10.1176/ps.44.4.381

Karam, G., Itani, L., Fayyad, J., Karam, A., Mneimneh, Z., \& Karam, E. (2016). Prevalence, correlates, and treatment of mental disorders among Lebanese older adults: A national study. The American Journal of Geriatric Psychiatry, 24(4), 278-286. https://doi.org/10.1016/j.jagp 2015.10.006

Karlsson, B. B. S., Klenfeldt, I. F. B. S., Sigstrom, R. B. S., Waern, M., Ostling, S., Gustafson, D., \& Skoog, I. M. D. (2009). Prevalence of social phobia in non-demented elderly from a Swedish population study. The American Journal of Geriatric Psychiatry, 17(2), 127-135. https:// doi.org/10.1097/JGP.0b013e3181860051

Karlsson, B., Sigström, R., Östling, S., Waern, M., Börjesson-Hanson, A., \& Skoog, I. (2016). DSM-4 and DSM-5 prevalence of social anxiety disorder in a population sample of older people. The American Journal of Geriatric Psychiatry, 24(12), 1237-1245. https://doi.org/10.1016/j .jagp.2016.07.023

Kelley-Moore, J. A., Schumacher, J. G., Kahana, E., \& Kahana, B. (2006). When do older adults become "Disabled"? Social and health antecedents of perceived disability in a panel study of the oldest old. Journal of Health and Social Behavior, 47(2), 126-141. https://doi.org/10.1177/ 002214650604700203

Kirmizioglu, Y., Dogan, O., Kugu, N., \& Akyüz, G. (2009). Prevalence of anxiety disorders among elderly people. International Journal of Geriatric Psychiatry, 24(9), 1026-1033. https://doi.org/10.1002/gps.2215

Klenfeldt, I. F., Karlsson, B., Sigstrom, R., Backman, K., Waern, M., Ostling, S., Gustafson, D., \& Skoog, I. (2014). Prevalence of obsessivecompulsive disorder in relation to depression and cognition in an elderly population. The American Journal of Geriatric Psychiatry, 22(3), 301308. https://doi.org/10.1016/j.jagp.2012.09.004

Kogan, J. N., Edelstein, B. A., \& McKee, D. R. (2000). Assessment of anxiety in older adults: Current status. Journal of Anxiety Disorders, 14(2), 109-132. https://doi.org/10.1016/S0887-6185(99)00044-4

Kohn, R., Vicente, B., Saldivia, S., Rioseco, P., \& Torres, S. (2008). Psychiatric epidemiology of the elderly population in Chile. The American Journal of Geriatric Psychiatry, 16(12), 1020-1028. https://doi .org/10.1097/JGP.0b013e31818a0e1c

Lenze, E. J., \& Wetherell, J. L. (2009). Bringing the bedside to the bench, and then to the community: A prospectus for intervention research in late-life anxiety disorders. International Journal of Geriatric Psychiatry, 24(1), 1-14. https://doi.org/10.1002/gps.2074 
Lenze, E. J., Wetherell, J. L., \& Andreescu, C. (2011). Anxiety disorders. In C. E. Coffey, J. L. Cummings, M. S. George, \& D. Weintraub (Eds.), The American Psychiatric Publishing textbook of geriatric neuropsychiatry (pp. 499-516). American Psychiatric Publishing, Inc.

Lindesay, J., \& Banerjee, S. (1993). Phobic disorders in the elderly. A comparison of three diagnostic systems. International Journal of Geriatric Psychiatry, 8, 387-394. https://doi.org/10.1002/gps.930080504

Lindesay, J., Briggs, K., \& Murphy, E. (1989). The guy's age concern survey: Prevalence rates of cognitive impairment, depression and anxiety in an urban elderly community. The British Journal of Psychiatry, 155(3), 317-329. https://doi.org/10.1192/bjp.155.3.317

Marquié, J. C., Jourdan-Boddaert, L., \& Huet, N. (2002). Do older adults underestimate their actual computer knowledge? Behaviour \& Information Technology, 21(4), 273-280. https://doi.org/10.1080/01449290 21000020998

Maulik, P. K., Mascarenhas, M. N., Mathers, C. D., Dua, T., \& Saxena, S. (2011). Prevalence of intellectual disability: A meta-analysis of population based studies. Research in Developmental Disabilities, 32(2), 419436. https://doi.org/10.1016/j.ridd.2010.12.018

Miloyan, B., Byrne, G. J., \& Pachana, N. A. (2015). Threshold and subthreshold generalized anxiety disorder in later life. The American Journal of Geriatric Psychiatry, 23(6), 633-641. https://doi.org/10 .1016/j.jagp.2014.08.010

Mohammadi, M. R., Ghanizadeh, A., Rahgozar, M., Noorbala, A. A., Davidian, H., Afzali, H. M., Naghavi, H. R., Yazdi, S. A. B., Saberi, S. M., Mesgarpour, B., Akhondzadeh, S., Alaghebandrad, J., \& Tehranidoost, M. (2004). Prevalence of obsessive compulsive disorder in Iran. BMC Psychiatry, 4, Article 2. https://doi.org/10.1186/1471-244X-4-2

Mohlman, J., Bryant, C., Lenze, E. J., Stanley, M. A., Gum, A., Flint, A., Beekman, A. T. F., Loebach Wetherell, J., Thorp, S. R., \& Craske, M. G. (2012). Improving recognition of late life anxiety disorders in diagnostic and statistical manual of mental disorders, fifth edition: Observations and recommendations of the advisory committee to the lifespan disorders work group. International Journal of Geriatric Psychiatry, 27(6), 549-556. https://doi.org/10.1002/gps.2752

Mohlman, J., Lauderdale, S., \& Wuthrich, V. (2020). Subscales of the fear survey schedule-III in community dwelling older adults-relations to clinical and cognitive measures. Clinical Gerontologist, 43(3), 281-294. https://doi.org/10.1080/07317115.2019.1571554

Myers, I. K., Weissman, M. M., Tischler, G. L., Holzer, C. E., III, Leaf, P. I., Orvaschel, H., Anthony, J. C., Boyd, J. H., Burke, J. D., Kramer, M., \& Stoltzman, R. (1984). Six-month prevalence of psychiatric disorders in three communities. Archives of General Psychiatry, 41(10), 959-967. https://doi.org/10.1001/archpsyc.1984.01790210041006

Neugarten, B. L. (1974). Age groups in American society and the rise of the young-old. The Annals of the American Academy of Political and Social Science, 415(11), 187-198. https://doi.org/10.1177/000271627 441500114

Nilsson, J., Ostling, S., Waern, M., Karlsson, B., Sigstrom, R., Guo, X., \& Skoog, I. (2012). The 1-month prevalence of generalized anxiety disorder according to DSM-IV, DSM-V, and ICD-10 among nondemented 75-year-olds in Gothenburg, Sweden. The American Journal of Geriatric Psychiatry, 20(11), 963-972. https://doi.org/10.1097/JGP $.0 \mathrm{~b} 013 \mathrm{e} 318252 \mathrm{e} 749$

Nilsson, J., Sigström, R., Östling, S., Waern, M., \& Skoog, I. (2019). Changes in the expression of worries, anxiety, and generalized anxiety disorder with increasing age: A population study of 70 to 85 -year-olds. International Journal of Geriatric Psychiatry, 34(2), 249-257. https:// doi.org/10.1002/gps.5012

Pachana, N. (2008). Ageing and psychological disorders. In E. Rieger (Ed.), Abnormal psychology (pp. 421-457). McGraw-Hill.

Palmer, B. W., Jeste, D. V., \& Sheikh, J. L. (1997). Anxiety disorders in the elderly: $D S M-I V$ and other barriers to diagnosis and treatment.
Journal of Affective Disorders, 46(3), 183-190. https://doi.org/10.1016/ S0165-0327(97)00146-8

Pless Kaiser, A., Cook, J. M., Glick, D. M., \& Moye, J. (2019). Posttraumatic stress disorder in older adults: A conceptual review. Clinical Gerontologist, 42(4), 359-376. https://doi.org/10.1080/07317115.2018 .1539801

Pratt, L. A., Druss, B. G., Manderscheid, R. W., \& Walker, E. R. (2016). Excess mortality due to depression and anxiety in the United States: Results from a nationally representative survey. General Hospital Psychiatry, 39, 39-45. https://doi.org/10.1016/j.genhosppsych.2015.12.003

Préville, M., Boyer, R., Grenier, S., Dube, M., Voyer, P., Punti, R., Baril, M. C., Streiner, D. L., Cairney, J., Brassard, J., \& Brassard, J. (2008). The epidemiology of psychiatric disorders in Quebec's older adult population. Canadian Journal of Psychiatry, 53(12), 822-832. https:// doi.org/10.1177/070674370805301208

Préville, M., Lamoureux-Lamarche, C., Vasiliadis, H. M., Grenier, S., Potvin, O., Quesnel, L., Gontijo-Guerra, S., Mechakra-Tahiri, S. D., \& Berbiche, D. (2014). The 6-month prevalence of posttraumatic stress syndrome PTSD among older adults: Validity and reliability of the PTSD scale. Canadian Journal of Psychiatry, 59(10), 548-555. https:// doi.org/10.1177/070674371405901008

R Core Team. (2018). R: A language and environment for statistical computing. R Foundation for Statistical Computing. Retrieved from http://www.R-project.org/

Regier, D. A., Boyd, H. J., Burke, J. D., Rae, D. S., Myers, J. K., Kramer, M., Robins, L. N., George, L. K., Karno, M., \& Locke, B. Z. (1988). One-month prevalence of mental disorders in the United States. Archives of General Psychiatry, 45, 977-986. https://doi.org/10.1001/archpsyc .1988 .01800350011002

Reynolds, K., Pietrzak, R. H., El-Gabalawy, R., Mackenzie, C. S., \& Sareen, J. (2015). Prevalence of psychiatric disorders in U.S. older adults: Findings from a nationally representative survey. World Psychiatry, 14(1), 74-81. https://doi.org/10.1002/wps.20193

Ritchie, K., Artero, S., Beluche, I., Ancelin, M. L., Mann, A., Dupuy, A. M., Malafosse, A., \& Boulenger, J.-P. (2004). Prevalence of DSM-IV psychiatric disorder in the French elderly population. The British Journal of Psychiatry, 184(2), 147-152. https://doi.org/10.1192/bjp.184.2 .147

Ritchie, K., Norton, J., Mann, A., Carriere, I., \& Ancelin, M. L. (2013). Late-onset agoraphobia: General population incidence and evidence for a clinical subtype. The American Journal of Psychiatry, 170(7), 790798. https://doi.org/10.1176/appi.ajp.2013.12091235

Rivas-Vazquez, R. A., Saffa-Biller, D., Ruiz, I., Blais, M. A., \& RivasVazquez, A. (2004). Current issues in anxiety and depression: Comorbid, mixed, and subthreshold disorders. Professional Psychology: Research and Practice, 35(1), 74-83. https://doi.org/10.1037/0735-7028 .35.1.74

Schaub, R. T., \& Linden, M. (2000). Anxiety and anxiety disorders in the old and very old-Results from the Berlin aging study BASE. Comprehensive Psychiatry, 41(2), 48-54. https://doi.org/10.1016/S0010440X(00)80008-5

Scheffer, A. C., Schuurmans, M. J., van Dijk, N., van der Hooft, T., \& de Rooij, S. E. (2008). Fear of falling: Measurement strategy, prevalence, risk factors and consequences among older persons. Age and Ageing, 37(1), 19-24. https://doi.org/10.1093/ageing/afm169

Schwarzer, G. (2007). meta: An R package for meta-analysis. $R$ News, 73, $40-45$.

Sheehan, D. V., Lecrubier, Y., Sheehan, K. H., Amorim, P., Janavs, J., Weiller, E., . . D Dunbar, G. C. (1998). The Mini-International Neuropsychiatric Interview (M. I. N. I.): The development and validation of a structured diagnostic psychiatric interview for DSM-IV and ICD-10. The Journal of Clinical Psychiatry, 59(Suppl. 20), 22-33.

Sigström, R., Östling, S., Karlsson, B., Waern, M., Gustafson, D., \& Skoog, I. (2011). A population- based study on phobic fears and 
DSM-IV specific phobia in 70-year olds. Journal of Anxiety Disorders, 25(1), 148-153. https://doi.org/10.1016/j.janxdis.2010.08.014

Spitzer, R. L., Kroenke, K., Williams, J. B., \& Löwe, B. (2006). A brief measure for assessing generalized anxiety disorder: The GAD-7. Archives of Internal Medicine, 166(1), 1092-1097. https://doi.org/10.1001/ archinte.166.10.1092

Trollor, J. N., Anderson, T. M., Sachdev, P. S., Brodaty, H., \& Andrews, G. (2007). Prevalence of mental disorders in the elderly: The Australian national mental health and well-being survey. The American Journal of Geriatric Psychiatry, 15(6), 455-466. https://doi.org/10.1097/JGP .0b013e3180590ba9

van Zelst, W. H., de Beurs, E., Beekman, A. T., Deeg, D. J., \& van Dyck, R. (2003). Prevalence and risk factors of posttraumatic stress disorder in older adults. Psychotherapy and Psychosomatics, 72, 333-342. https:// doi.org/10.1159/000073030

Viechtbauer, W. (2010). Conducting meta-analyses in R with the metafor package. Journal of Statistical Software, 36(3), 1-48. https://doi.org/10 $.18637 /$ jss.v036.i03

Viechtbauer, W., \& Cheung, M. L. (2010). Outlier and influence diagnostics for meta-analysis. Research Synthesis Methods, 1(2), 112-125. https://doi.org/10.1002/jrsm.11

Volkert, J., Schulz, H., Härter, M., Wlodarczyk, O., \& Andreas, S. (2013). The prevalence of mental disorders in older people in Western countries-A meta-analysis. Ageing Research Reviews, 12(1), 339-353. https://doi.org/10.1016/j.arr.2012.09.004

Wang, P. S., Berglund, P., \& Kessler, R. C. (2000). Recent care of common mental disorders in the United States: Prevalence and conformance with evidence-based recommendations. Journal of General Internal Medicine, 15, 284-292. https://doi.org/10.1046/j.1525-1497.2000.9908044.x

Wild, B., Eckl, A., Herzog, W., Niehoff, D., Lechner, S., Maatouk, I., Schellberg, D., Brenner, H., Muller, H., \& Löwe, B. (2014). Assessing generalized anxiety disorder in elderly people using the GAD7 and GAD-2 scales: Results of a validation study. The American Journal of Geriatric Psychiatry, 22(10), 1029-1038. https://doi.org/10.1016/j.jagp .2013.01.076

Wolitzky-Taylor, K. B., Castriotta, N., Lenze, E. J., Stanley, M. A., \& Craske, M. G. (2010). Anxiety disorders in older adults: A comprehensive review. Depression and Anxiety, 27(2), 190-211. https://doi.org/10 $.1002 /$ da. 20653

World Health Organization. (1990). Composite International Diagnostic Interview (CIDI) (Version 1.0).

World Health Organization. (2018). Ageing and health. Retrieved from https://www.who.int/news-room/fact-sheets/detail/ageing-and-health

Xavier, F., Ferraza, M., Argimon, I., Trentini, C. M., Poyares, D., Bertollucci, P. H., Bisol, L. W., \& Moriguchi, E. H. (2002). The DSM-IV "minor depression" disorder in the oldest old: Prevalence rate, sleep patterns, memory function and quality of life in elderly people of Italian descent in Southern Brazil. International Journal of Geriatric Psychiatry, 17(2), 107-116. https://doi.org/10.1002/gps.517

Xiao, S., Lewis, M., Mellor, D., McCabe, M., Byrne, L., Wang, T., . . . Dong, S. (2016). The China longitudinal ageing study: Overview of the demographic, psychosocial and cognitive data of the Shanghai sample. Journal of Mental Health, 25(2), 131-136. https://doi.org/10.3109/ 09638237.2015.1124385

\section{Appendix A}

\section{Final Search Strings Databases}

\section{Final Search String PsycINFO}

(DE "Anxiety" OR DE “Anxiety Disorders" OR DE "Generalized Anxiety Disorder" OR DE "Obsessive Compulsive Disorder" OR DE "Panic Disorder" OR DE "Post-Traumatic Stress" OR DE "Panic Attack" OR DE "Social Anxiety" OR DE "Social Phobia" OR DE "Agoraphobia" OR TI anxiety OR TI "anxiety disorder", OR TI "anxiety symptom"” OR TI "subthreshold anxiety" OR TI "subsyndromal anxiety" OR TI "subclinical anxiety" OR TI "specific phobia" OR TI "simple phobia" OR TI "Phobic disorder", OR TI "generalized anxiety disorder" OR TI agoraphobia OR TI "panic disorder" OR TI "panic attack" " OR TI "social phobia" OR TI "social anxiety disorder" OR TI "obsessive compulsive disorder" OR TI "obsessive-compulsive disorder" OR TI "Posttraumatic Stress Disorder" OR TI "Post-traumatic Stress Disorder" OR TI "GAD" OR TI "OCD" OR TI "PTSD" OR TI panic OR TI worry $\mathrm{OR} A B$ anxiety $\mathrm{OR} A \mathrm{AB}$ "anxiety disorder" $\mathrm{OR} A \mathrm{AB}$ "anxiety symptom*" OR AB "subthreshold anxiety" OR AB "subsyndromal anxiety" OR AB "subclinical anxiety" $O R A B$ "specific phobia" OR AB "simple phobia" OR AB "Phobic disorder", OR $A B$ "generalized anxiety disorder" $O R A B$ agoraphobia $O R A B$ "panic disorder" OR AB "panic attack" ${ }^{*}$ OR AB "social phobia" $\mathrm{OR} A B$ "social anxiety disorder" $\mathrm{OR} A B$ "obsessive compulsive disorder" OR AB "obsessive-compulsive disorder" OR AB "Posttraumatic Stress Disorder" OR AB "Post-traumatic Stress Disorder" OR AB "GAD" OR AB "OCD" OR AB "PTSD" OR AB panic OR AB worry OR KW anxiety OR KW "anxiety disorder", OR KW "anxiety symptom"”, OR KW "subthreshold anxiety" OR $\mathrm{KW}$ "subsyndromal anxiety" OR KW "subclinical anxiety" OR $\mathrm{KW}$ "specific phobia" OR KW "simple phobia" OR KW "Phobic disorder" " OR KW "generalized anxiety disorder" OR KW agoraphobia OR KW "panic disorder" OR KW "panic attack"” OR $\mathrm{KW}$ "social phobia" OR KW "social anxiety disorder" OR KW "obsessive compulsive disorder" OR KW "obsessive-compulsive disorder" OR KW "Posttraumatic Stress Disorder" OR KW "Posttraumatic Stress Disorder" or KW "GAD" OR KW "OCD" OR KW "PTSD" OR KW panic OR KW worry) 
AND

(DE "epidemiology" OR TI prevalen* OR TI incidence OR TI occurrence OR TI epidemiology OR TI frequency OR AB epidemiology $\mathrm{OR} A B$ prevalen* $\mathrm{OR} A B$ incidence $\mathrm{OR} A B$ occurrence OR AB frequency OR KW epidemiology OR KW prevalen* OR $\mathrm{KW}$ incidence OR KW occurrence OR KW frequency)

\section{AND}

(TI "older adults" OR TI elder* OR TI senior* OR TI geriatric* OR TI aging OR TI "older people" OR TI "late* life" OR TI midlife OR AB "older adults" OR AB elder* OR AB senior* OR $\mathrm{AB}$ geriatric* OR AB aging OR AB "older people" OR AB "late* life" OR AB midlife OR KW "older adults" OR KW elder* OR KW senior* OR KW geriatric* OR KW aging OR KW "older people" OR KW "late* life" or KW midlife)

\section{Filters}

- Publication year: 1952-2020

- Source types: Academic Journals

- Language: English

- Age: adulthood (18 years \& older), aged (65 years \& older), middle age ( $40-64$ years), very old ( 85 years $\&$ older)

\section{Final Search String Cochrane}

(Prevalence [mesh] OR incidence [mesh] OR epidemiology [mesh] OR prevalen* [ti, ab, kw] OR incidence [ti, ab, kw] OR epidemiology [ti, ab, kw] OR occurrence [ti, ab, kw] OR frequency [ti, ab, kw])

AND

(Anxiety [ti, ab, kw] OR "anxiety disorder", [ti, ab, kw] OR "anxiety symptom"” [ti, ab, kw] OR "subclinical anxiety" [ti, ab, kw] OR "subthreshold anxiety" [ti, ab, kw] OR "subsyndromal anxiety" [ti, ab, kw] OR "specific phobia" [ti, ab, kw] OR "simple phobia" [ti, ab, kw] OR "phobic disorder" " [ti, ab, kw] OR "generalized anxiety disorder" [ti, ab, kw] OR "GAD” [ti, ab, kw] OR "agoraphobia" [ti, ab, kw] OR "panic disorder" [ti, ab, kw] OR "panic attack" " [ti, ab, kw] OR "social phobia' OR "social anxiety disorder" or OCD [ti, ab, kw] OR "obsessive-compulsive disorder" [ti, ab, kw] OR "Obsessive compulsive disorder" [ti, ab, kw] OR "Posttraumatic stress disorder" [ti, ab, kw] OR "Post-traumatic stress disorder" [ti, ab, kw] OR PTSD [ti, ab, kw] OR panic [ti, ab, kw] OR worry [ti, ab, kw] OR anxiety [mesh] OR anxiety disorders [mesh] OR Phobic disorders [mesh] OR Phobia, Social [mesh] OR Panic disorder [mesh] OR Agoraphobia [mesh] OR Obsessive-compulsive disorder [mesh] OR Panic [mesh] OR Stress Disorders, Posttraumatic [mesh])

AND

("older adults" [ti, ab, kw] OR elder" [ti, ab, kw] OR aging [ti, $\mathrm{ab}, \mathrm{kw}$ ] OR senior* [ti, ab, kw] OR geriatric ${ }^{*}[\mathrm{ti}, \mathrm{ab}, \mathrm{kw}]$ OR “:older people" [ti, ab, kw] OR "late* life" [ti, ab, kw] OR midlife [ti, ab, kw] OR OR Aged [mesh] OR Aging [mesh] OR Aged, 80 and over [mesh] OR Middle Aged [mesh])

\section{Final Search String Pubmed}

1. "Anxiety" [Majr:NoExp]) OR "Anxiety Disorders" [Majr:NoExp]) OR "Phobic Disorders" [Majr:NoExp]) OR "Phobia, Social" [Majr:NoExp]) OR "Panic Disorder" [Majr:NoExp]) OR “Agoraphobia” [Majr:NoExp]) OR “Obsessive-Compulsive Disorder" [Majr:NoExp]) OR "Panic" [Majr:NoExp]) OR “Stress Disorders, PostTraumatic" [Majr:NoExp])

2. anxiety[Title/Abstract] OR "anxiety disorder" [Title/ Abstract] OR "anxiety symptom"” [Title/Abstract] OR "subthreshold anxiety" [Title/Abstract] OR "subsyndromal anxiety" [Title/Abstract] OR "subclinical anxiety" [Title/Abstract] OR "specific phobia" [Title/Abstract] OR "simple phobia" [Title/Abstract] OR "phobic disorder*" [Title/Abstract] OR "generalized anxiety disorder" [Title/Abstract] OR agoraphobia [Title/Abstract] OR "panic disorder" [Title/Abstract] OR "panic attack" " [Title/Abstract] OR "social phobia" [Title/Abstract] OR "social anxiety disorder" [Title/Abstract] OR "obsessive compulsive disorder" [Title/Abstract] OR "obsessive-compulsive disorder" [Title/Abstract] OR "Posttraumatic Stress Disorder" [Title/Abstract] OR "Post-traumatic Stress Disorder" [Title/Abstract] OR "GAD" [Title/Abstract] OR "OCD” [Title/Abstract] OR "PTSD" [Title/Abstract] OR panic[Title/Abstract] OR worry[Title/Abstract]

3. "Prevalence" [Majr:NoExp]) OR "Incidence" [Majr: NoExp]) OR “Epidemiology” [Majr:NoExp])

4. Prevalen*[Title/Abstract] OR incidence[Title/Abstract] OR epidemiology[Title/Abstract] OR occurrence[Title/ Abstract] OR frequency[Title/Abstract]

5. “Aged" [Majr:NoExp]) OR (“Aging” [Majr:NoExp]) OR ("Aged, 80 and over" [Majr:NoExp]) OR "Middle aged” [Majr:NoExp])

6. "older adults" [Title/Abstract] OR elder*[Title/Abstract] OR senior*[Title/Abstract] OR geriatric*[Title/ Abstract] OR "older people" [Title/Abstract] OR "late" life[Title/Abstract] OR midlife[Title/Abstract] OR aging [Title/Abstract]

(\#1 OR \#2) AND (\#3 OR \#4) AND (\#5 OR \#6) 


\section{Filters}

- Year of publication: 1952-2020

- Language: English

- Humans

- Age:

o Adult: $19+$ years

o Adult: $19-44$ years

o Middle Aged + Aged: $45+$ years

o Middle Aged: 45-64 years

o Aged: $65+$ years

o 80 and over: $80+$ years

\section{Final Search String Web of Science}

$1 \mathrm{TI}=$ (anxiety OR "anxiety disorder" ${ }^{*}$ OR "anxiety symptom*" OR "subthreshold anxiety" OR "subsyndromal anxiety" OR "subclinical anxiety" OR "specific phobia" OR "simple phobia" OR "Phobic Disorder", OR "generalized anxiety disorder" OR "agoraphobia" OR "panic disorder" OR "panic attack" "OR "social phobia" OR "social anxiety disorder" OR "obsessive compulsive disorder" OR "obsessive-compulsive disorder" OR "Posttrau- matic Stress Disorder" OR "Post-traumatic Stress Disorder" OR "GAD” OR “OCD” OR "PTSD” OR panic OR worry)

$2 \mathrm{TS}=$ (anxiety OR "anxiety disorder" OR "anxiety symptom*" OR "subthreshold anxiety" OR "subsyndromal anxiety" OR "subclinical anxiety" OR "specific phobia" OR "simple phobia" OR "Phobic Disorder"” OR "generalized anxiety disorder" OR "agoraphobia" OR "panic disorder" OR "panic attack" OR "social phobia" OR "social anxiety disorder" OR "obsessive compulsive disorder" OR "obsessive-compulsive disorder" OR "Posttraumatic Stress Disorder" OR "Post-traumatic Stress Disorder" OR "GAD” OR “OCD” OR "PTSD” OR panic OR worry)

$3 \mathrm{TI}=$ ("older adults" OR elder* OR senior" OR geriatric* OR aging OR "older people" OR "late* life" OR midlife)

$4 \mathrm{TI}=$ (prevalen* $\mathrm{OR}$ incidence OR epidemiology OR occurrence $\mathrm{OR}$ frequency)

(\#1 OR \#2) AND (\#3) AND (\#4)

\section{Filters}

- Language: English

- Document types: articles

- Year of publication: 1952-2020

\section{Appendix B}

Articles Included in Subgroup Analyses

Table B1

Articles Included in the Subgroup Analyses

\begin{tabular}{|c|c|c|c|c|}
\hline Disorder & $\begin{array}{l}\text { Articles }\left(\mathrm{IDs}^{\mathrm{a}}\right) \text { reporting } \\
\text { prevalence rates for age } \\
\text { category 55-64 }(N)\end{array}$ & $\begin{array}{c}\text { Articles (IDs) reporting } \\
\text { prevalence rates for age category } \\
65-74(N)\end{array}$ & $\begin{array}{l}\text { Articles (IDs) reporting } \\
\text { prevalence rates for age } \\
\text { category } 75-84(N)\end{array}$ & $\begin{array}{l}\text { Articles (IDs) } \\
\text { reporting } \\
\text { prevalence rates } \\
\text { for age category } \\
\quad 85+(N)\end{array}$ \\
\hline AGO & $4,7(6,170)$ & $1,4,7,24(5,859)$ & $1,4(960)$ & $1,4(174)$ \\
\hline GAD & $2,4,12,43,44(4,180)$ & $1,2,4,12,23,25,43,44(4,806)$ & $1,2,4,12,23,31,44(3,806)$ & $1,4,32,46(701)$ \\
\hline OCD & $2,3,28(3,259)$ & $1,2,23,24(2,570)$ & $1,2,23(1,634)$ & $1(52)$ \\
\hline PD & $2,3,4,5,35,43(13,421)$ & $1,2,4,7,25,27,35,43,(11,454)$ & $1,4,35(3,633)$ & $1,3,35(1,044)$ \\
\hline PTSD & $35^{\mathrm{a}}(5,135)$ & $23,25,34(4,210)$ & $23,35(2,735)$ & $35(870)$ \\
\hline SAD & $4,7,35(11,305)$ & $1,4,7,21,23,35(10,179)$ & $1,4,22,23,35(4,895)$ & $1,4,35(1,044)$ \\
\hline SP & $4,35(6,249)$ & $1,4,23,35,39(6,062)$ & $1,4,23,35(3,695)$ & $1,4,35(1,044)$ \\
\hline
\end{tabular}

Note. $\mathrm{AGO}=$ agoraphobia; $\mathrm{GAD}=$ generalized anxiety disorder; $\mathrm{OCD}=$ obsessive compulsive disorder; $\mathrm{PD}=$ panic disorder; $\mathrm{PTSD}=$ posttraumatic stress disorder; $\mathrm{SAD}=$ social anxiety disorder; $\mathrm{SP}=$ specific phobia.

${ }^{\text {a }}$ See Table 1 (main text) for articles and their assigned ID number. 


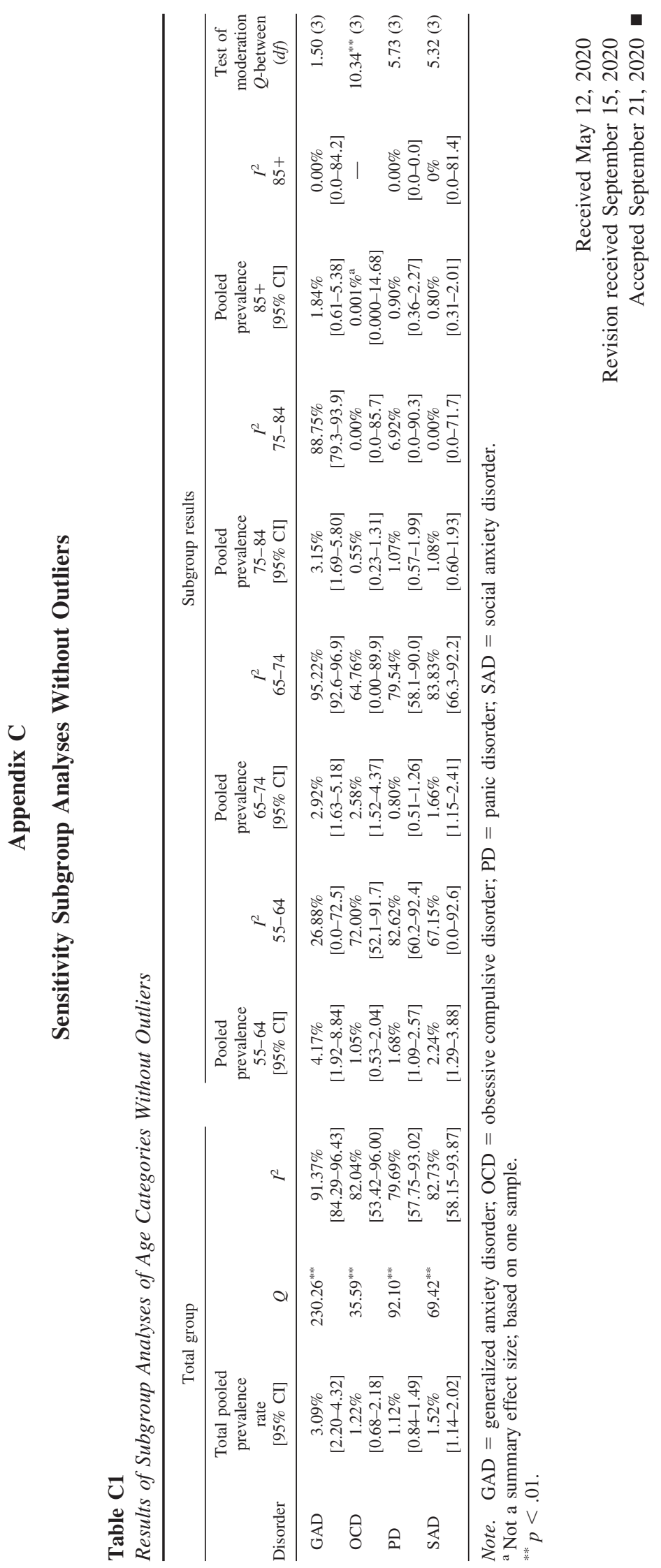

